FHWA/IN/JTRP-2009/11

Final Report

AUTOMATED VEHICLE LOCATION (AVL) FOR ROAD CONDITION REPORTING

Bob G. McCullouch

Michelle Leung

Won Jin Kang

September 2009 
Final Report

FHWA/IN/JTRP-2009/11

\title{
AUTOMATED VEHICLE LOCATION (AVL) FOR ROAD CONDITION REPORTING
}

\author{
by \\ Bob G. McCullouch \\ Principal Investigator \\ Research Scientist \\ Michelle Leung \\ Web Multi-Media Developer \\ and \\ Won Jin Kang \\ Web Multi-Media Developer \\ School of Civil Engineering \\ Purdue University \\ Joint Transportation Research Program \\ Project No. C-36-67ZZZ \\ File No. 9-10-77 \\ SPR-2922 \\ Conducted in Cooperation with the \\ Indiana Department of Transportation \\ and the Federal Highway Administration \\ U.S. Department of Transportation
}

The contents of this report reflect the views of the authors, who are responsible for the facts and the accuracy of the data presented herein. The contents do not necessarily reflect the official views or policies of the Indiana Department of Transportation or the Federal Highway Administration at the time of publication. This report does not constitute a standard, specification, or regulation.

Purdue University

West Lafayette, IN 47907

September 2009 
TECHNICAL REPORT STANDARD TITLE PAGE

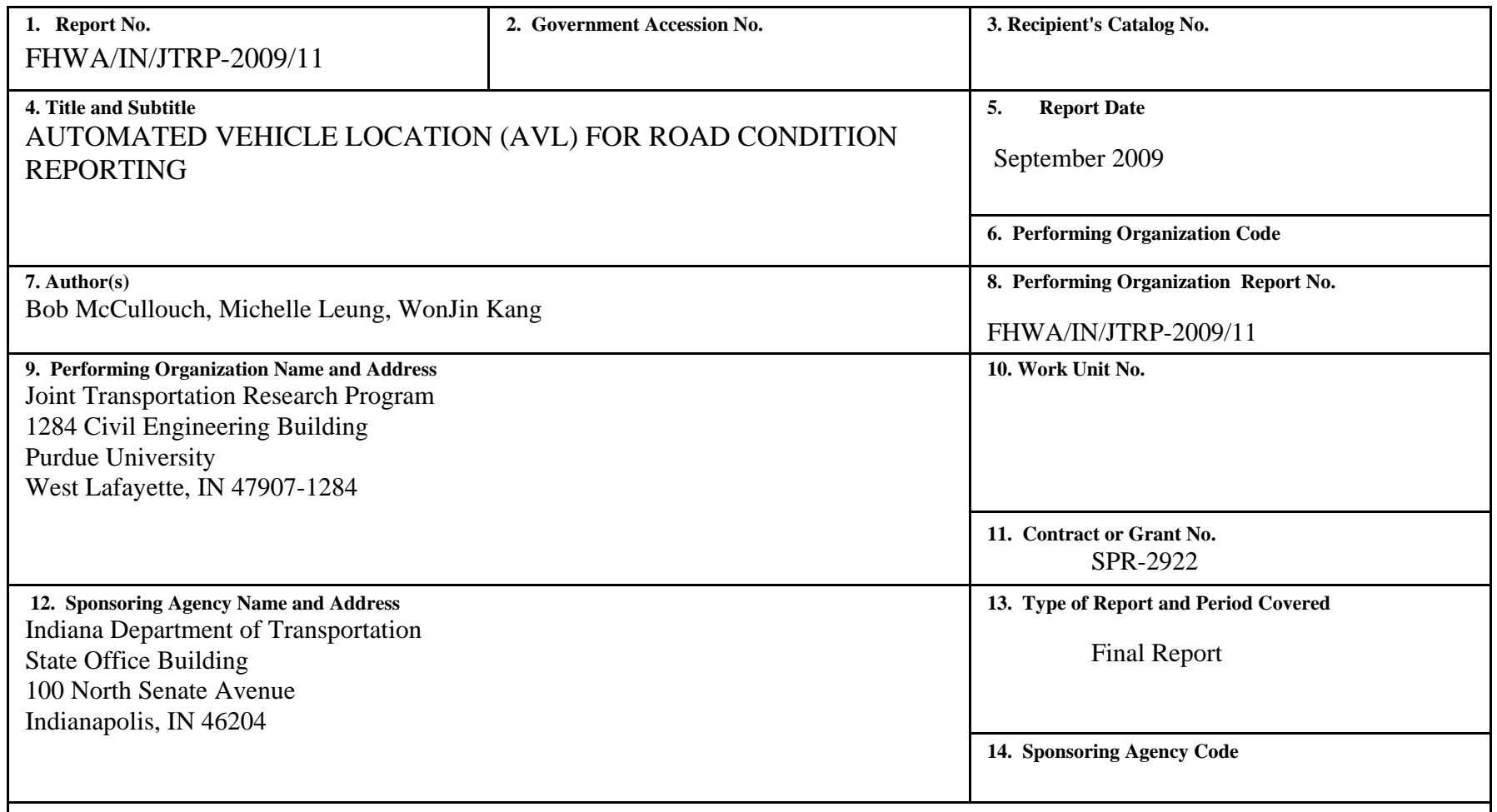

15. Supplementary Notes

Prepared in cooperation with the Indiana Department of Transportation and Federal Highway Administration.

\section{Abstract}

This project developed an AVL system for INDOT that utilized the statewide wireless network, SAFE-T. This option was chosen after doing a cost analysis of commercial AVL systems that use cellular data communications. The system developed provides real time information collected during snow and ice removal. Information includes weather and road conditions, truck speed, amount of chemicals spread, time, location, plow position, and road temperature. This information is displayed on INDOT GIS maps available through a browser on the INDOT network. The data is also transferred to the MDSS that INDOT uses in winter activities. This system experienced significant data transfer problems and consequently was eliminated as a viable AVL alternative. Therefore other commercial AVL systems were evaluated in this study.

Other activities included investigating other hardware options for data collection and data transfer. Also, a hotspot method for data transfer was tested to do batch data transfer. A summer AVL application for paint stripping was developed.

Two other commercial systems were evaluated, IWAPI and ThomTech. The IWAPI system was evaluated over three winter seasons and Thomtech for the 08-09 season. Both systems experienced data transfer problems which seems to be the biggest issue with AVL systems. Overall most users were satisfied with how the systems operated and with the information being collected and reported.

The project exposed issues that exist with all types of AVL systems. There are plusses and minuses, and costs and benefits. These are described in the report. One outcome is that AVL systems are not a panacea, they offer better information and benefits, but are they economically justifiable? An internal INDOT study was performed during the 08-09 season that shows a savings of $\$ 10,000,000$ in salt costs that can be attributed to some degree the use of AVL and MDSS.

\begin{tabular}{|c|c|c|c|c|}
\hline \multicolumn{2}{|c|}{$\begin{array}{l}\text { 17. Key Words } \\
\text { Winter operations, snow and ice, maintenance, snow plow, AVL, } \\
\text { MDSS }\end{array}$} & \multicolumn{3}{|c|}{$\begin{array}{l}\text { 18. Distribution Statement } \\
\text { No restrictions. This document is available to the public through the } \\
\text { National Technical Information Service, Springfield, VA } 22161\end{array}$} \\
\hline $\begin{array}{l}\text { 19. Security Classif. (of this report) } \\
\text { Unclassified }\end{array}$ & \multicolumn{2}{|c|}{$\begin{array}{c}\text { 20. Security Classif. (of this page) } \\
\text { Unclassified }\end{array}$} & $\begin{array}{r}\text { 21. No. of Pages } \\
41\end{array}$ & 22. Price \\
\hline
\end{tabular}




\section{TABLE OF CONTENTS}

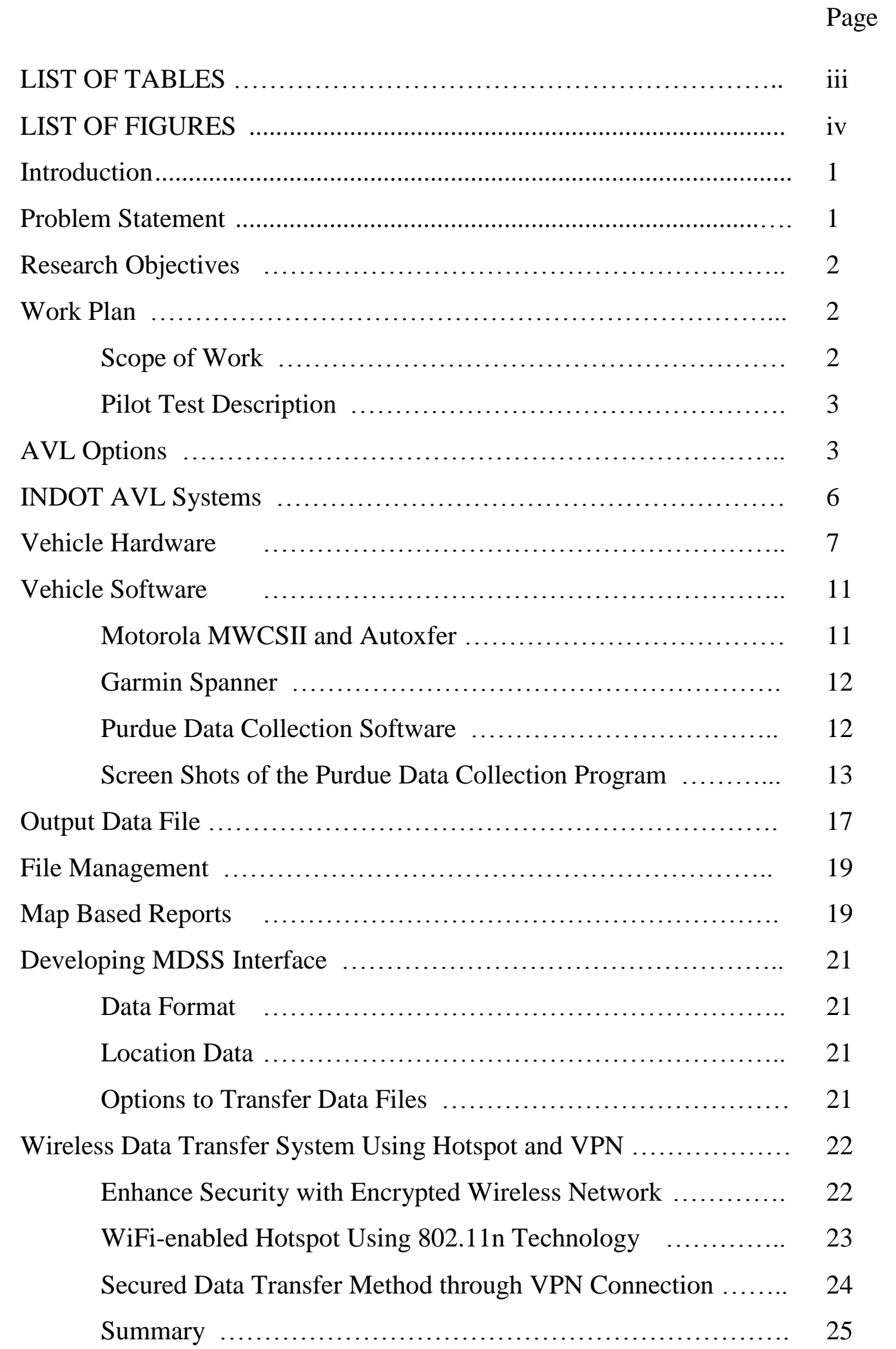




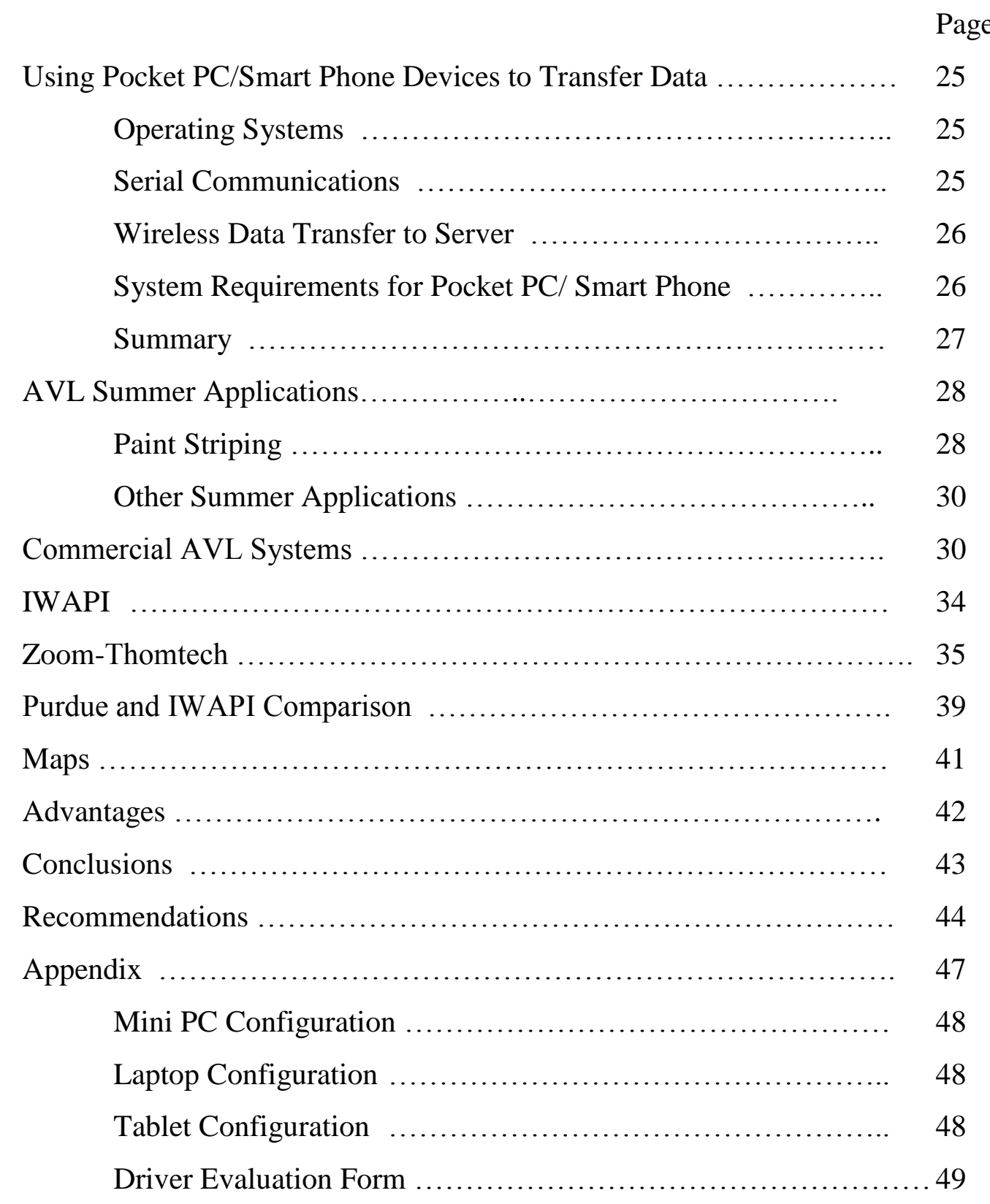




\section{LIST OF TABLES}

Table

Page

Table 1 AVL Options Cost Comparison $\ldots \ldots \ldots \ldots \ldots \ldots \ldots . \ldots . \ldots$

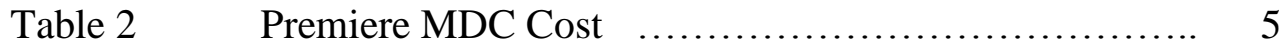

Table 3 Cost Comparison 5-8 Years .......................... 6

Table 4 GPS Equipment Comparison ...................... 8

Table $5 \quad$ Computer Cost Comparison $\quad \ldots \ldots \ldots \ldots \ldots \ldots \ldots \ldots . \ldots . \ldots . \ldots . \ldots 11$

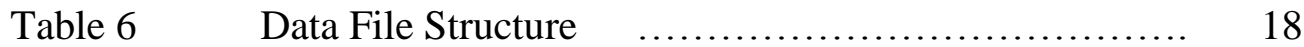

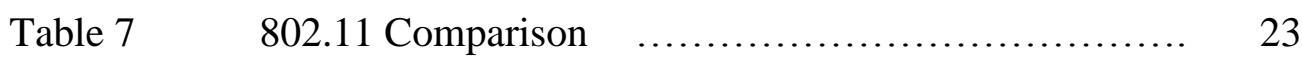

Table $8 \quad$ File Transmission Test $\ldots \ldots \ldots \ldots \ldots \ldots \ldots \ldots \ldots \ldots \ldots . \ldots . \ldots . \ldots . \ldots 24$

Table $9 \quad$ Cellular Service Comparison ........................ 26

Table $10 \quad$ Cost Comparison for 1000 Trucks ................. 27

Table $11 \quad$ TerraFleet Base System $\ldots \ldots \ldots \ldots \ldots \ldots \ldots \ldots \ldots \ldots . . \ldots \ldots$

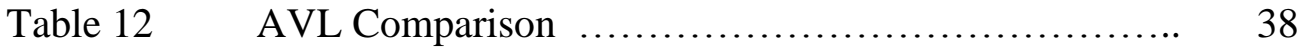

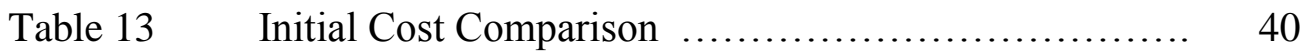

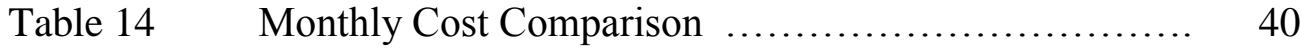

Table 15 Purdue and IWAPI Feature Comparison $\ldots . . . \ldots \ldots \ldots . . .41$ 


\section{LIST OF FIGURES}

Figure Page

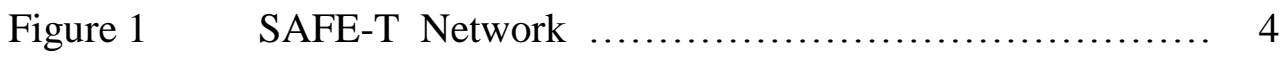

Figure $2 \quad$ INDOT AVL System $\ldots \ldots \ldots \ldots \ldots \ldots \ldots \ldots \ldots \ldots \ldots . \ldots \ldots$

Figure $3 \quad$ Vehicle Hardware ................................ 8

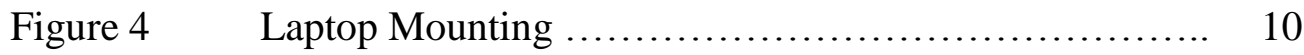

Figure $5 \quad$ Mini PC Screen Mounting ........................ 10

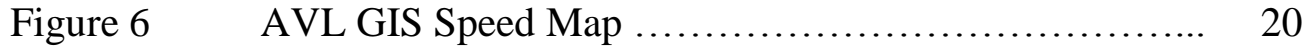

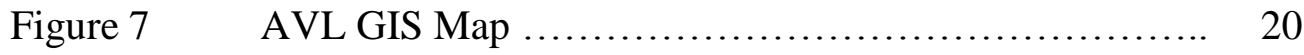

Figure $8 \quad$ Hotspot Option ................................ 22

Figure $9 \quad$ Data Transfer with Mobile Devices ................... 26

Figure $10 \quad$ Paint Stripe Input Screen $\ldots \ldots \ldots \ldots \ldots \ldots \ldots \ldots \ldots \ldots . \ldots . \ldots . \ldots . \ldots 28$

Figure 11 Paint Usage Calculation Screen .................... 29

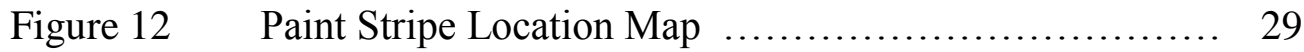

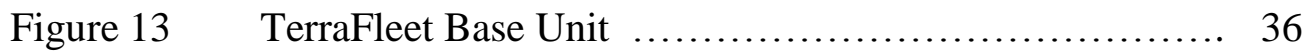

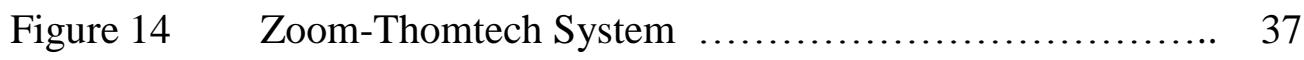

Figure $15 \quad$ TerraFleet Touch Screen System $\ldots \ldots \ldots \ldots \ldots \ldots \ldots \ldots . \ldots . \ldots . \ldots$

Figure $16 \quad$ MDSS Map .................................. 42 


\section{Introduction}

Many factors influence INDOT's snow and ice removal efforts. Weather is the most important, but others include: what chemicals to use, their application rates, what strategies to use, what equipment to use and how to apply chemicals, are a few. Most of these are management decisions. Some of these management decisions can be improved through the use of technology, and in particular the use of Automated Vehicle Location (AVL) technology.

AVL technology provides the capability for tracking the location of maintenance vehicles and recording their activities while patrolling. AVL's can track the type of chemicals applied, their application rates, road conditions, and application times. All of these influence snow and ice removal and should be analyzed during winter activities. This project will be used by INDOT to evaluate this technology.

This technology has been used by other organizations and has proven to be effective and efficient. Another benefit in using AVL and collecting the activities of the vehicles electronically; is data can be transferred electronically into INDOT's Maintenance Decision Support System (MDSS). This will eliminate the need for the operator to record this information on crew day cards or taper logs and manually transferring it.

\section{Problem Statement}

Inefficient snow and ice removal efforts have serious consequences. Annually in the United States 1.5 million vehicle accidents occur resulting in 800,000 injuries, and 7000 fatalities. Also, 500 million hours of traffic delay result.

Directing, managing, and analyzing winter activities at INDOT can be improved through the use of AVL technology. The current methodology of recording and entering this information occurs "after the fact." The lack of current information can be detrimental. Also, documenting INDOT vehicle location and their activities is crucial in determining what time to make another application and what and how much chemical to apply. Due to lack of timely information INDOT can be improperly using vehicles and wasting chemicals.

AVL provides the capability to electronically record the location and activities of winter maintenance vehicles. This data can be transferred electronically and save time, improve data accuracy, and improve the feedback to INDOT managers that are responsible for making decisions on winter activities.

Other organizations that have used this technology report quantifiable improvements in their winter activities. These include improved reporting data, better utilization of equipment, and savings in fuel and chemical costs. A summary of AVL utilization by other organizations is found in the Appendix. Also, with data electronically imported into MDSS, management decisions can be better made in a more timely manner. 
A future consideration could include real-time information via a web site that would provide motorists with up-to-the-minute truck locations and roadway conditions, all possible with AVL.

\section{Research Objectives}

The primary objective of the project is to obtain an AVL system, perform a field test, and develop and test a procedure to electronically transfer the collected data into INDOT's MDSS. By doing so, this project will provide the understanding and background on the issues and costs to implement this into INDOT's operations. It will also provide options for automating the transfer of data electronically into INDOT's MDSS.

\section{Work Plan}

\section{$\underline{\text { Scope of Work }}$}

- Review the availability of AVL systems.

- Evaluate the experience of other DOT organizations.

- Evaluate and select a wireless data transfer system.

- Setup and run a pilot at INDOT Subdistricts (Monticello and Columbus).

- Evaluate the AVL hardware/software to check for compatibility to existing INDOT systems and equipment and automated data transfer to MDSS.

- Evaluate the feasibility and practicality of collecting weather data from snow plow operators.

- Evaluate the ability to report current road conditions.

- Develop an implementation plan that estimates costs and describes how to establish this statewide.

First, a test of the AVL will be performed to check for usability of the system such as data transmission, vehicle monitoring, and data processing, as well as evaluating the hardware and software to be used.

Second, a pilot implementation at two INDOT Subdistricts will be conducted during the research period so as to evaluate the system's effect on road maintenance, efficiency of information regarding road conditions and management of snow removal fleet during two winter seasons.

Third, the research will then describe the pilot system implemented, and discuss the lessons learned from the implementation of the system.

Fourth, a report will be developed that describes the project results and an implementation program. 


\section{$\underline{\text { Pilot Test Description }}$}

The pilot system consists of control software and AVL equipment including in-vehicle GPS receiver, post-processor, and a GPS board to be installed in a main control station. GIS software will also be needed for presentation of the post-processed data on a digitized local map.

Once the pilot system is installed, the system operation can be monitored 24 hours and the post-processed GPS data will be stored in a database for later review and evaluation.

Based on the test results, qualitative and quantitative analyses will be performed considering associated costs spent during the system development phase and potential quantifiable benefits from the developed system.

\section{AVL Options}

Two AVL options were considered and studied. Option 1 uses an AVL service provider where data is transferred via cellular service. There are numerous AVL service providers. Information was collected and a cost comparison done. This cost comparison is shown below in Tables 1-3. This system consists of proprietary software and a monthly service of $\$ 40$ to $\$ 60$ per vehicle.

Option 2 consists of using the Indiana SAFE-T wireless network to transfer data. The Indiana network is used by the State Police and a coverage map is shown in Figure 1. Coverage is available in the northern two thirds of the state. Installation is proceeding in the southern third of the state. Data is transferred through a $800 \mathrm{mhz}$ radio network with a transmission rate of $19.2 \mathrm{~Kb}$ that is managed by Motorola. 


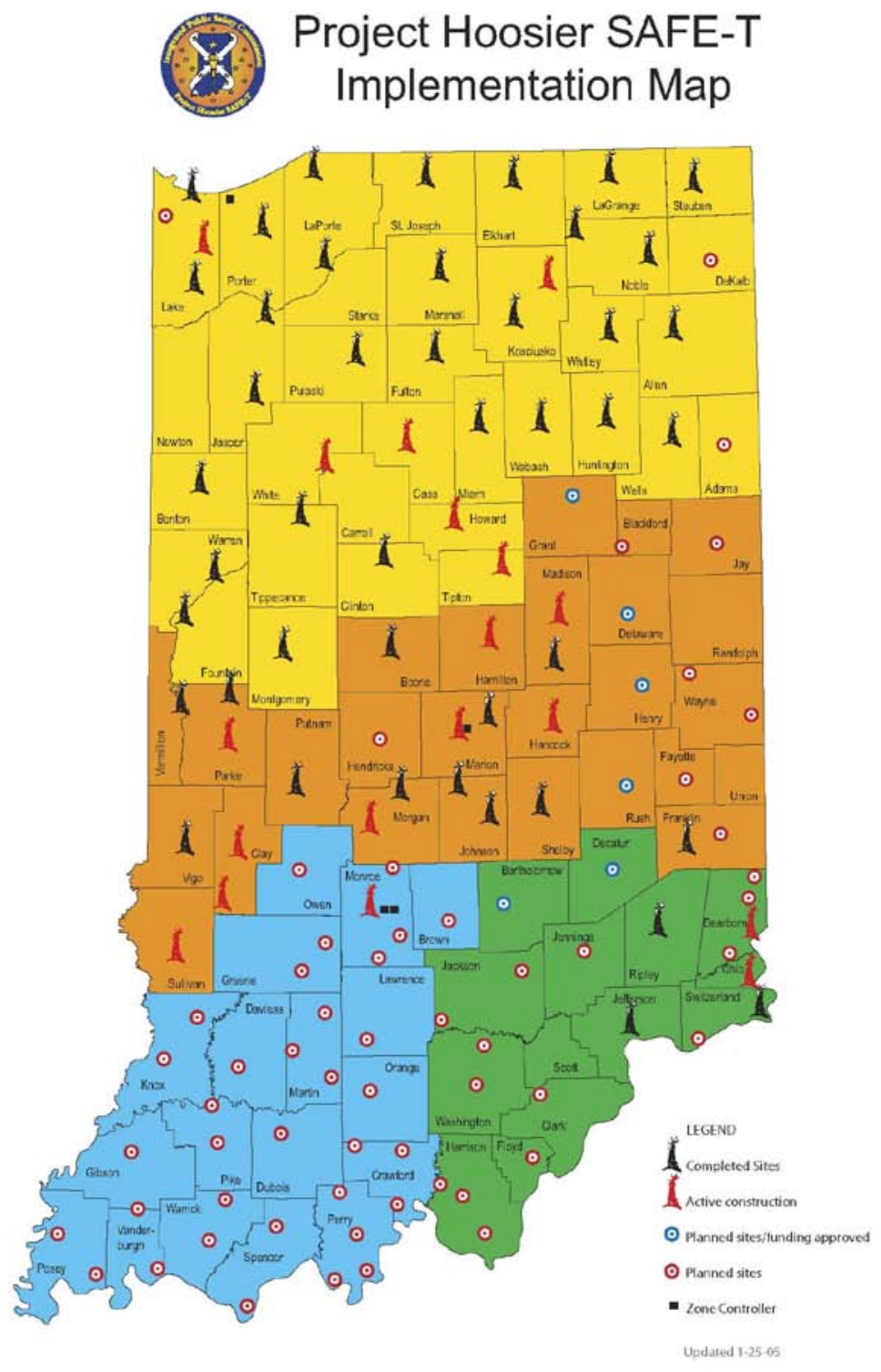

Figure 1 - SAFE-T Network

INDOT has approximately 1100 vehicles that participate in winter operations. Motorola did a data traffic study with this number of vehicles and determined that the data network has sufficient capacity to support this application. All equipment and software would be owned by INDOT. 


\section{Cost Comparison (1,000 trucks for 5 years)}

\begin{tabular}{|c|c|c|c|c|c|c|}
\hline Options & Hardware & Parts & Model / Vendor & Cost per Part & $\underline{\text { Subtotal }}$ & $\begin{array}{c}\text { Total } \\
\text { Maximum } \\
\text { Cost }\end{array}$ \\
\hline \multirow[t]{2}{*}{ Option 1} & $\begin{array}{l}\text { In-Vehicle } \\
\text { Equipment }\end{array}$ & $\begin{array}{l}\text { GPS receiver } \\
+ \\
\text { Modem }+ \\
\text { Data Terminal }\end{array}$ & Multiple Vendors & $\$ 500.00$ - \$900.00 / vehicle & \multirow{2}{*}{$\begin{array}{l}\$ 3,400.00- \\
\$ 4,500.00 \text { per } \\
\text { vehicle }\end{array}$} & \multirow[t]{2}{*}{$\$ 4,500,000.00^{1}$} \\
\hline & \multicolumn{2}{|l|}{ Service Fee } & Multiple Vendors & $\begin{array}{l}\$ 2,700.00-\$ 3,600.00 / 5 \text { years / } \\
\text { vehicle } \\
(\$ 45.00-\$ 60.00 \text { / month / vehicle })\end{array}$ & & \\
\hline \multirow{7}{*}{ Option 2} & \multirow{4}{*}{$\begin{array}{l}\text { In-Vehicle } \\
\text { Equipment }\end{array}$} & GPS receiver & GPS 18 / Garmin & $\$ 130.00$ & \multirow{4}{*}{$\begin{array}{l}\$ 3355.00 \text { per } \\
\text { vehicle }\end{array}$} & \multirow{7}{*}{$\$ 3,753,390.00^{2}$} \\
\hline & & $\begin{array}{l}\text { Radio Modem } \\
+ \text { Antenna }\end{array}$ & VRM 850 / Motorola & $\$ 1,900.00$ & & \\
\hline & & $\begin{array}{l}\text { Rugged } \\
\text { Laptop }\end{array}$ & ML 850 / Motorola & $\$ 1,200.00$ & & \\
\hline & & $\begin{array}{l}\text { IP Setting } \\
\text { Software }\end{array}$ & MCSW2 / Motorola & $\$ 125.00$ & & \\
\hline & \multicolumn{2}{|l|}{ Base Station } & AVL server & $\$ 5,000$ & \multirow{3}{*}{$\$ 398,390.00$} & \\
\hline & \multicolumn{2}{|c|}{$\begin{array}{l}\text { Map-Based Control } \\
\text { Software }\end{array}$} & PU/INDOT & $\$ 0$ & & \\
\hline & \multicolumn{2}{|c|}{ File Transfer Module } & $\begin{array}{l}\text { PDMC Application } \\
\text { Software / Motorola }\end{array}$ & $\$ 393,390.00^{3}$ & & \\
\hline
\end{tabular}

\section{Table 1 - AVL Options Cost Comparison}

1. $\$ 4,500.00 \times 1,000$ trucks, assuming the service fee is not changing for 5 years

2. $\$ 3,355.00 \times 1,000$ trucks + AVL server $(\$ 5,000)+$ PDMC Application Software $(\$ 393,390.00)$

3. See the following table for details

\section{Motorola PDMC Application Software (1,000 trucks for 5 years)}

\begin{tabular}{|c|c|c|c|c|c|}
\hline Year & Qty & Description & Cost & Subtotal & Total \\
\hline \multirow{3}{*}{ Year 1} & 1 & $\begin{array}{l}\text { Wireless File Transfer Server Module } \\
(\$ 16,130)\end{array}$ & \multicolumn{3}{|l|}{$\$ 16,130$} \\
\hline & 1,000 & Wireless File Transfer Client Module (\$260) & \multicolumn{3}{|l|}{$\$ 260,000$} \\
\hline & & Maintenance & \multicolumn{3}{|l|}{ Warranty } \\
\hline \multicolumn{4}{|c|}{ Motorola PMDC Application Software Subtotal (Year 1) } & \multicolumn{2}{|l|}{$\$ 276,130.00$} \\
\hline Year 2 & & Maintenance (10\% of Software Cost) & \multicolumn{3}{|l|}{$\$ 27,613$} \\
\hline Year 3 & & $\begin{array}{l}\text { Maintenance (10\% of Software Cost plus } 4 \% \\
\text { escalation) }\end{array}$ & \multicolumn{3}{|l|}{$\$ 28,718$} \\
\hline Year 4 & & $\begin{array}{l}\text { Maintenance (10\% of Software Cost plus } 4 \% \\
\text { escalation) }\end{array}$ & \multicolumn{3}{|l|}{$\$ 29,867$} \\
\hline Year 5 & & $\begin{array}{l}\text { Maintenance (10\% of Software Cost plus } 4 \% \\
\text { escalation) }\end{array}$ & \multicolumn{3}{|l|}{$\$ 31,062$} \\
\hline \multicolumn{4}{|c|}{ Motorola PMDC Software Maintenance Subtotal (Year 2 - Year 5) } & $\$ 117,260.00$ & \\
\hline \multicolumn{5}{|c|}{ Motorola PMDC Application Software Total (5 Years) } & $\$ 393,390.00$ \\
\hline
\end{tabular}

Table 2 - Premiere MDC Cost 
Cost Comparison after Year 5 between Option 1 and Option 2

\begin{tabular}{c|l|c|c|c}
\hline \multirow{2}{*}{ Year } & \multicolumn{2}{|c|}{ Option 1 } & \multicolumn{2}{c}{ Option 2 } \\
\cline { 2 - 5 } & Additional Cost & Total & Additional Cost & Total \\
\hline \hline Year 5 & & $\$ 4,500,000.00$ & & $\$ 3,753,390.00$ \\
\hline Year 6 & $+\$ 720,000^{1}$ & $\$ 5,220,000.00$ & $+\$ 32,304.00^{2}$ & $\$ 3,785,694.00$ \\
\hline Year 7 & $+\$ 720,000$ & $\$ 5,940,000.00$ & $+\$ 33,596.00$ & $\$ 3,819,290.00$ \\
\hline Year 8 & $+\$ 720,000$ & $\$ 6,660,000.00$ & $+\$ 34,914.00$ & $\$ 3,854,204.00$ \\
\hline
\end{tabular}

1. Annual Service Fee $=\$ 720.00 /$ vehicle $/$ year $\times 1,000$ trucks $=\$ 720,000.00$ for Year 6

2. Annual Software Maintenance Cost (10\% of Software Cost plus $4 \%$ annual escalation) $=\$ 31,062.00$ (Year 5) x $1.04=\$ 32,304.00$ for Year 6

3. First year that Option 1 costs more than Option 3, assuming the service fee in Option 1 is not changing

Option 2 is considerably less expensive due to the monthly service charge required in Option 1.

\section{INDOT AVL System}

Since the cost differential between these options is significant option 2 was chosen. Figure 2 is a conceptual diagram of option 2.

The first winter test period, 2005-2006, experienced weather and system problems. With the weather, there were very few winter events at these two sub locations to test with. There were several system issues. One was driver interface. Inputting the login and password as well as wireless signal verification troubled the drivers. Also, there was a need to do spot treatments and cleanup activities that could not be reported. These modifications were made during the summer of 2006. Also, the Study Advisory Committee recommended the system be expanded to three locations and add six more trucks for the 2006 - 2007 season. The new location is to be Laporte and the truck distribution is:

$$
\begin{aligned}
& \text { Laporte - 4 } \\
& \text { Monticello - } 3 \\
& \text { Columbus - } 3
\end{aligned}
$$




\section{Conceptual Diagram of INDOT AVL Network Using SAFE-T Radio Network}

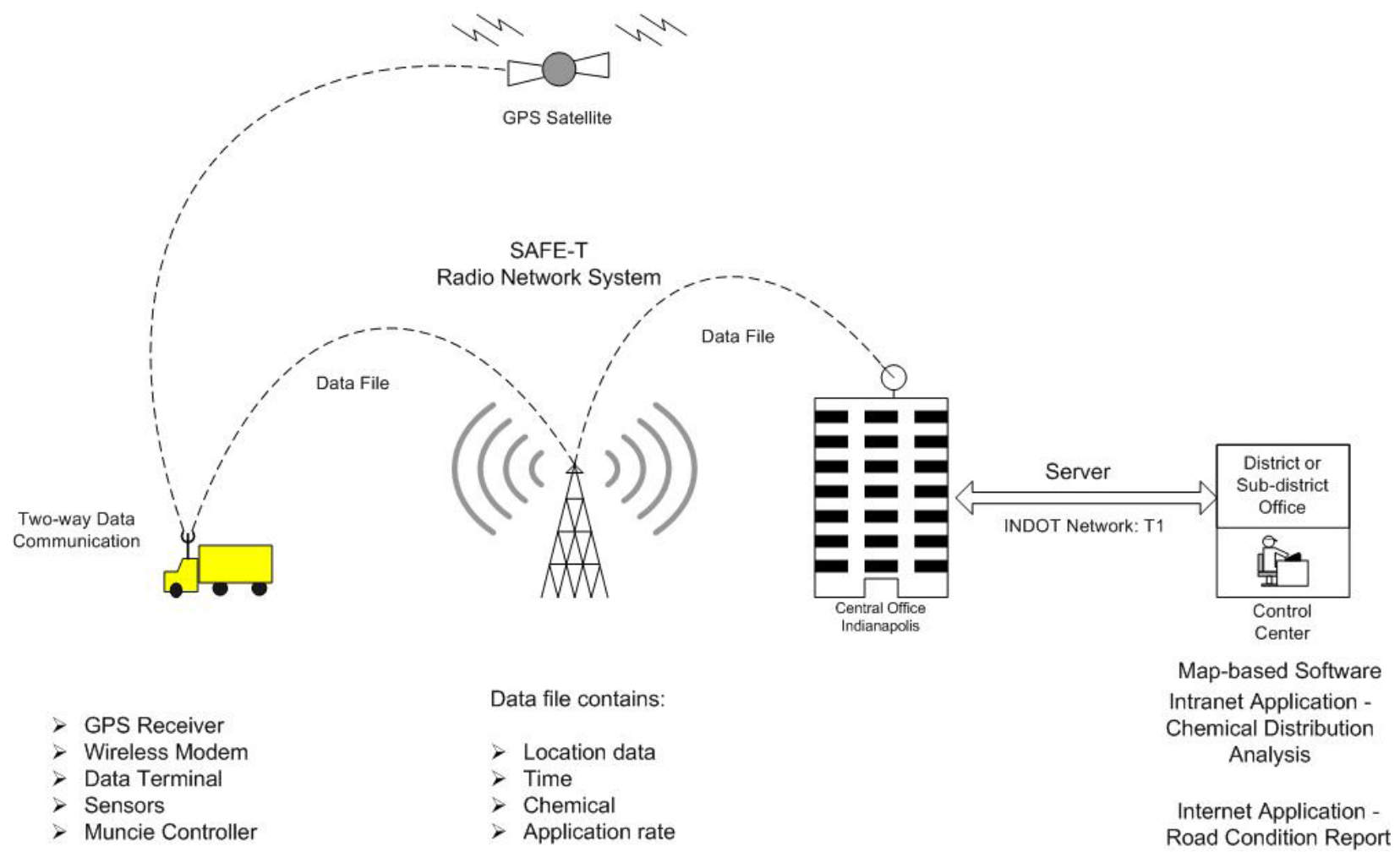

Figure 2 - INDOT AVL System

A more detailed description and explanation of this system is described next.

\section{Vehicle Hardware}

A similar conceptual view of the in-vehicle hardware is shown below in Figure 3. There are four main hardware components in the trucks. 


\section{AVL HARDWARE DIAGRAM}

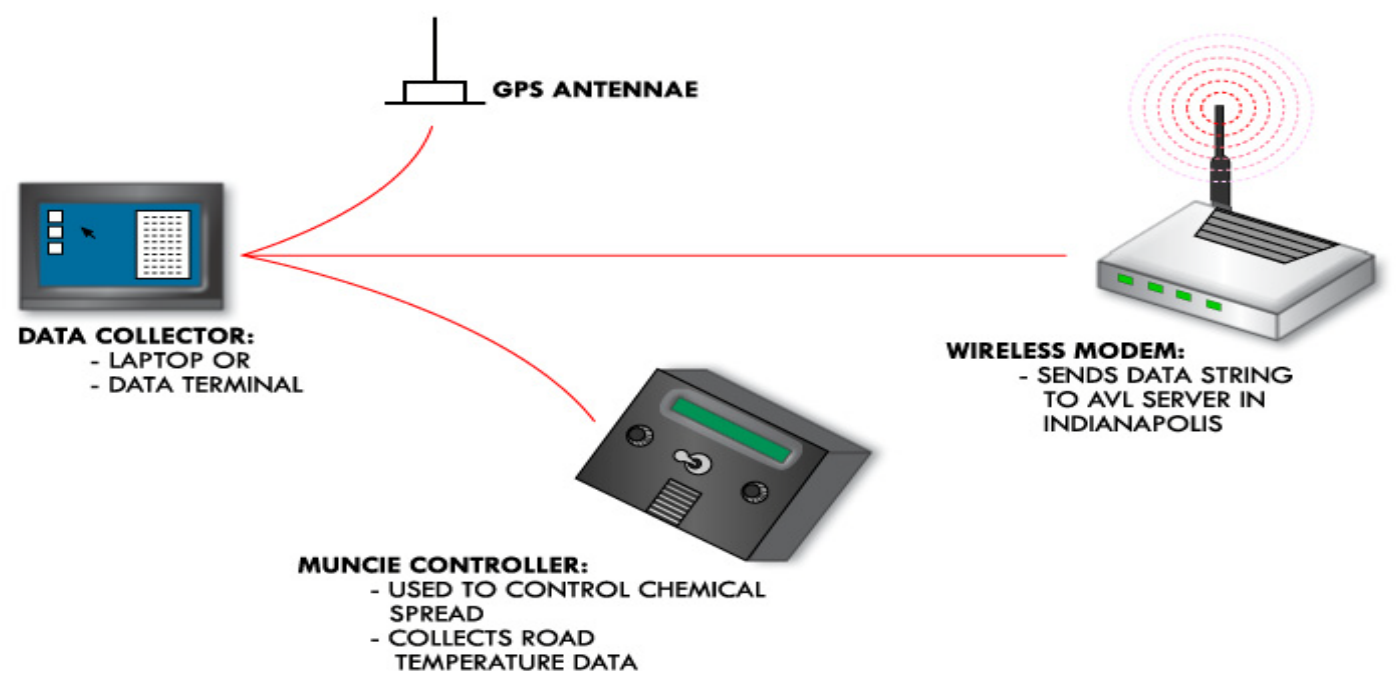

Figure 3 - Vehicle Hardware

\section{GPS Antennae}

Garmin GPS 18 receiver is a GPS OEM unit that receives location data from a satellite. This brand and model was chosen for its low cost and large operating temperature range. A comparison between GPS equipment is shown in the below table.

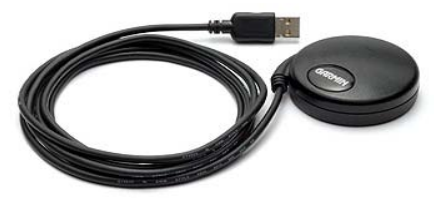

\begin{tabular}{|c|c|c|c|}
\hline & Pharos & Garmin & Delorme \\
\hline Model & iGPS-500 & GPS 18 OEM & Earthmate LT-20 \\
\hline Price & $\$ 100.00$ & $\$ 56.00$ & $\$ 100.00$ \\
\hline Sensitivity & $-159 \mathrm{dBm}$ & $-165 \mathrm{dBW}$ minimum & $145 \mathrm{dBm}$ \\
\hline Channels & $\begin{array}{l}12 \text { Channel all-in- } \\
\text { view tracking }\end{array}$ & $\begin{array}{c}12 \text { Channel } \\
\text { continuously tracks }\end{array}$ & 12 Channel \\
\hline Acquisition time & Cold: 35s; Hot: 1s & Cold: 45s; Hot: 15s & Cold: 38s; Hot: 3s \\
\hline WAAS & Yes & Yes & Yes \\
\hline $\begin{array}{l}\text { Dynamics (Max } \\
\text { velocity) }\end{array}$ & $\begin{array}{c}972 \text { knots }(1800 \\
\mathrm{km} / \mathrm{h})\end{array}$ & 999 knots & 1000 knots \\
\hline USB & Yes & Yes & Yes \\
\hline $\begin{array}{l}\text { Operating } \\
\text { temperature }\end{array}$ & $-4 \mathrm{~F}$ to $167 \mathrm{~F}$ & $-22 F$ to $176 F$ & $-40 \mathrm{~F}$ to $185 \mathrm{~F}$ \\
\hline Storage temperature & $-40 \mathrm{~F}$ to $194 \mathrm{~F}$ & $-40 \mathrm{~F}$ to $176 \mathrm{~F}$ & $-67 \mathrm{~F}$ to $212 \mathrm{~F}$ \\
\hline
\end{tabular}

Table 4 - GPS Equipment Comparison 


\section{Chemical Distribution Controller}

INDOT uses the Muncie Controller (MESP 402E) to control the distribution of chemicals from the winter vehicle. Through the course of the research project a temperature sensor and a plow position sensor were added to the vehicle. These sensor data are collected through the Muncie controller.

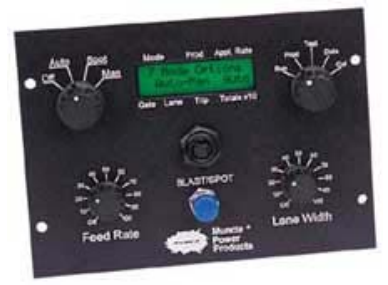

\section{Wireless modem}

Motorola modem (VRM 850, 800MHz 35W) transfers the data at regularly defined intervals from the truck to the AVL server in Indianapolis over the SAFE-T network. See Figure 2 conceptual diagram.

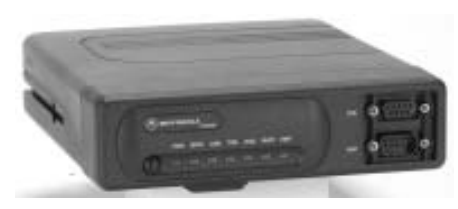

\section{Data Collector}

Three options for the in-vehicle data collector were tried and tested. A mini PC with touch screen monitor, a touch screen laptop, and an ultra mobile tablet PC were used as the computer data collection alternatives. The technical configuration for each device is in the Appendix.

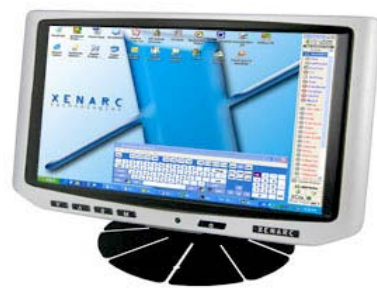

Xenarc in-vehicle mini PC

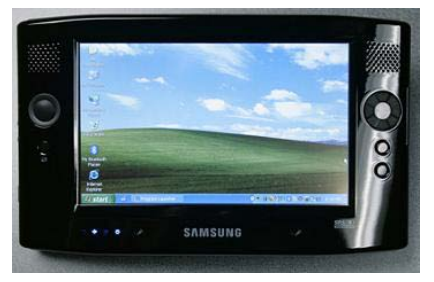

Samsung Q1 ultra mobile tablet PC

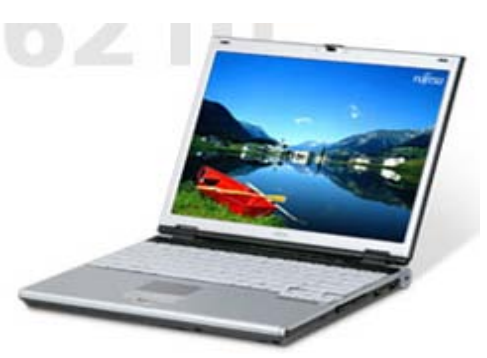

Fujitsu B6210 touch screen laptop

The mounting options for these devices varied by location. The below two images show the mounting of a laptop and the mini PC screen. 


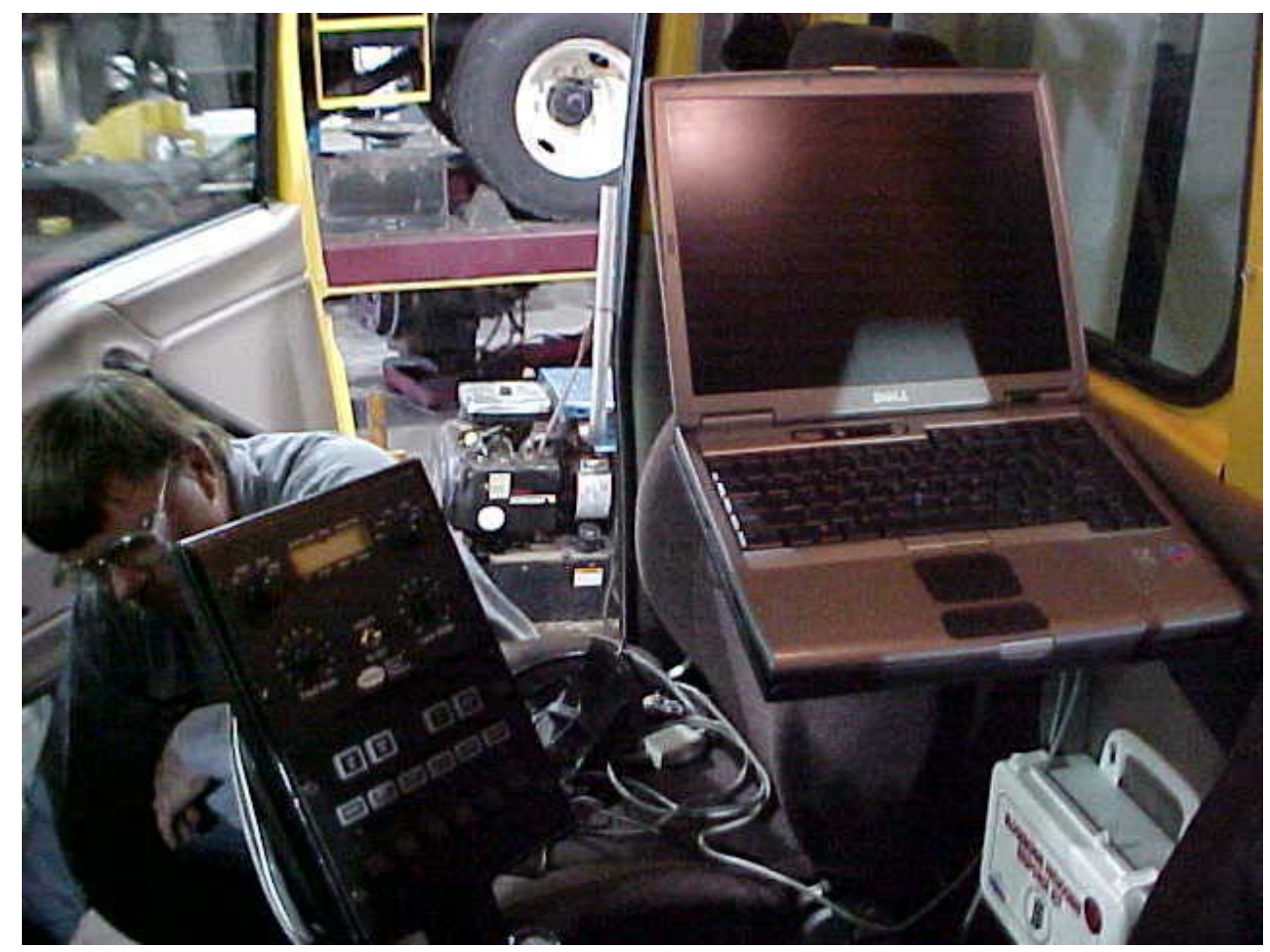

Figure 4 - Laptop mounting

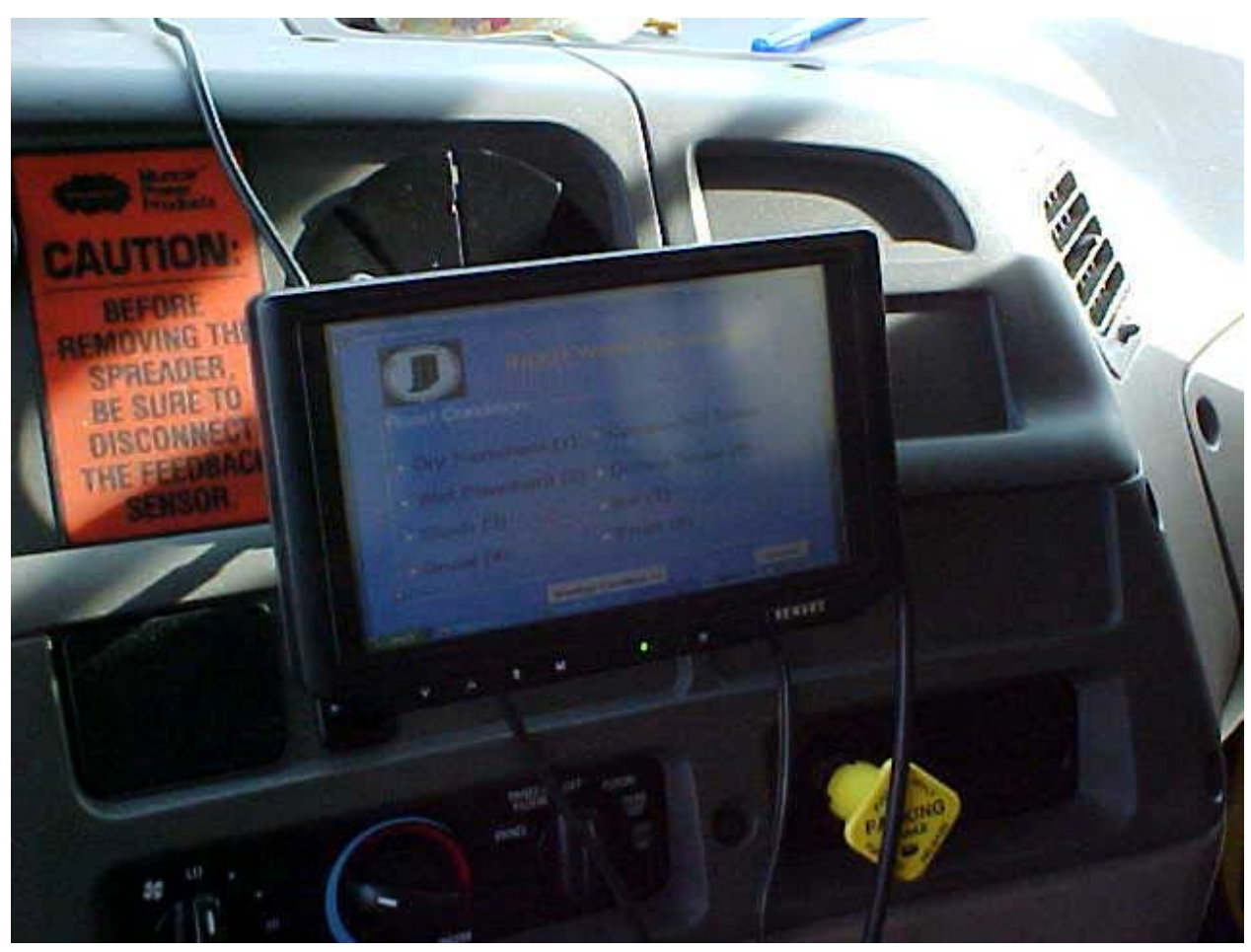

Figure 5 - Mini PC Screen Mounting 
Prices for these three computer options is shown in the below table.

\begin{tabular}{|c|c|c|c|}
\hline & Mini PC & Lifebook laptop & $\begin{array}{c}\text { Ultra Mobile } \\
\text { tablet }\end{array}$ \\
\hline Computer & $\$ 1359$ & $\$ 1466.43$ & $\$ 982.38$ \\
\hline GPS & $\$ 56$ & $\$ 56$ & $\$ 56$ \\
\hline $\begin{array}{c}\text { Modem, } \\
\text { software license, } \\
\text { preventive } \\
\text { maintenance }\end{array}$ & $\$ 2285+$ & $\$ 2285+$ & $\$ 2285+$ \\
\hline $\begin{array}{c}\text { Muncie Plow } \\
\text { sensor }\end{array}$ & $\$ 60$ & $\$ 60$ & $\$ 60$ \\
\hline $\begin{array}{c}\text { Muncie } \\
\text { Temperature sensor }\end{array}$ & $\$ 460$ & $\$ 460$ & $\$ 460$ \\
\hline $\begin{array}{c}\text { USB to serial cord } \\
\text { USB Hub }\end{array}$ & $\$ 34.99$ & $\$ 34.99 \times 2$ & $\$ 34.99 \times 2$ \\
\hline Inverter & $\$ 7$ A & $\$ 19.99$ & $\$ 19.99$ \\
\hline Splitter & $\$ 7.99$ & $\$ 79.97$ & $\$ 79.97$ \\
\hline Total & $\$ \mathbf{4 3 4 2 . 9 5 +}$ & $\$ \mathbf{4 5 0 5 . 3 6 +}$ & $\$ \mathbf{4 0 2 1 . 3 1 +}$ \\
\hline
\end{tabular}

Table 5 - Computer Cost Comparison

Software was developed to interface the collector with the other three hardware devices: Muncie controller, GPS antennae, and Motorola modem. A description of this software follows.

\section{Vehicle Software}

\section{Motorola MWCSII and Autoxfer}

This software is a Motorola product and it transfers data over the SAFE-T network. The MWCSII software connects the modem in the client (truck) to the Safe-T network. The Autoxfer program is responsible for sending data to the server at defined intervals. The time interval that was used in our application is three minutes. 


\section{Garmin Spanner}

The Garmin Spanner software writes the GPS data to a selected serial port. The data will then be collected through the Purdue Data Collecting software.

\section{Purdue Data Collection Software}

The Purdue Data Collecting Software was developed in Visual Basic 6. The program is activated at computer start-up. The first thing the program does is to start the Garmin Spanner program and the Motorola Autoxfer program. Both will run in the background. This software has a series of input screens for the driver, and combines the input with data from the Muncie controller and the GPS antennae. The combined data is sent every three minutes to the AVL server through the wireless network. The driver is required to input values for road and weather conditions and report road problem location as well as spot mode location.

\section{Input Screens}

There are two operation modes: (1) Chemical Spread and (2) Plowing Only. The Chemical Spread mode is used when the operation involves chemical spread with or without plowing. If no chemical spread occurs, no data is transferred. The Plowing Only mode is used when no chemicals are spread. The Muncie controller should be turned on in both modes.

Road Condition and Weather Condition

The driver has eight road and weather conditions to choose from:

Road Conditions

\begin{tabular}{|l|l|}
\hline Dry Pavement & Compacted Snow \\
\hline Wet Pavement & Drifted Snow \\
\hline Slush & Ice \\
\hline Snow & Frost \\
\hline
\end{tabular}

Weather Conditions

\begin{tabular}{|l|l|}
\hline Snow & Rain \\
\hline Blowing Snow & Drizzle \\
\hline Sleet & Fog \\
\hline Freezing Rain & No Precipitation \\
\hline
\end{tabular}


$\underline{\text { Screen Shots of the Purdue Data Collection Program }}$

A detailed explanation on how the software works is shown in the following screen shots.

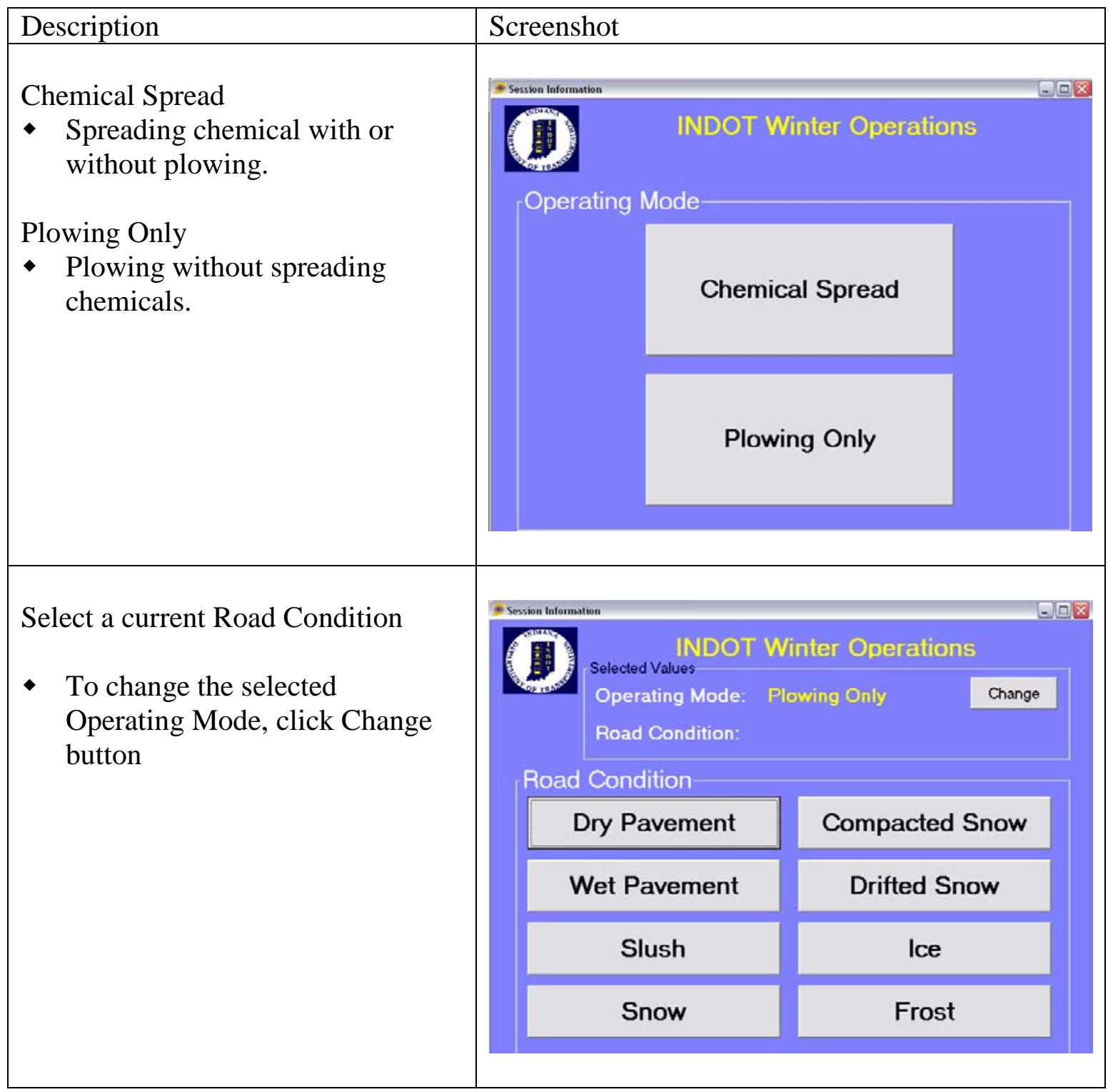




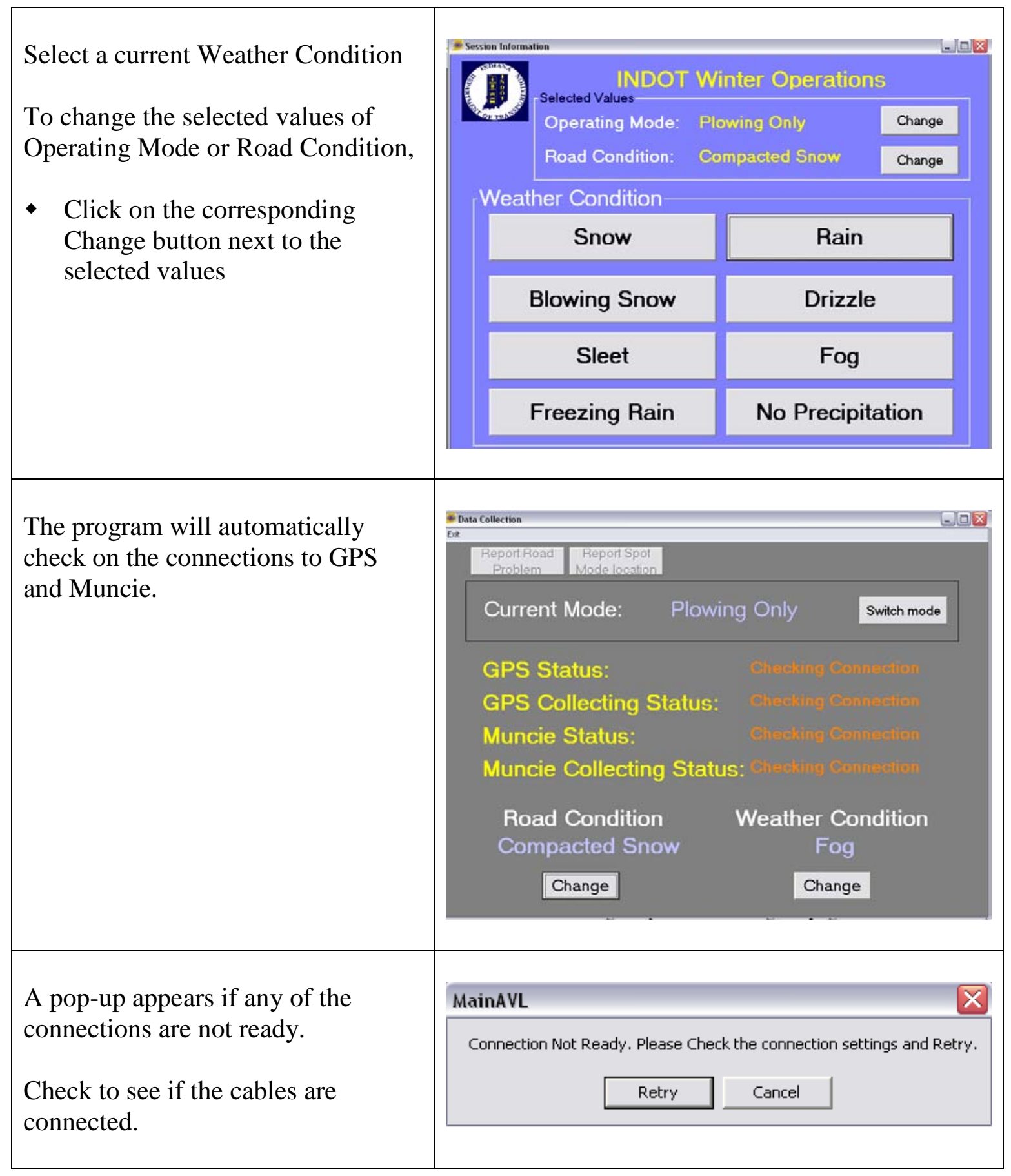


If both connections are good,

- The vehicle ID will appear on the top right corner.

- The program will automatically collect data from both devices.

- The flashing Collecting Data... will appear

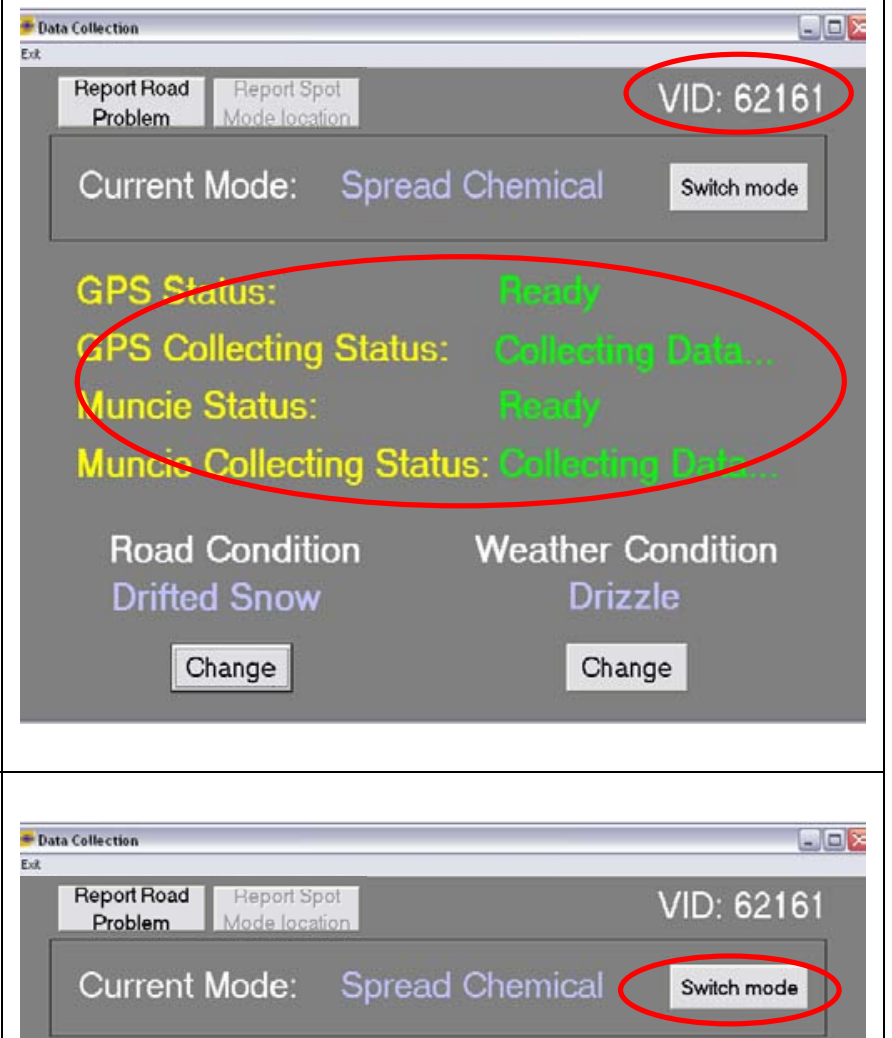

- Click on Switch mode button to switch between Spread Chemical and Plowing modes.

GPS Status:

GPS Collecting Status:

Muncie Status:

Muncie Collecting Status:

Road Condition

Drifted Snow

Change
Weather Condition

Drizzle

Change 
To change a road or weather condition

- Click on the Change button.

- The original selection is highlighted.

- Select the new condition, and it will be highlighted.

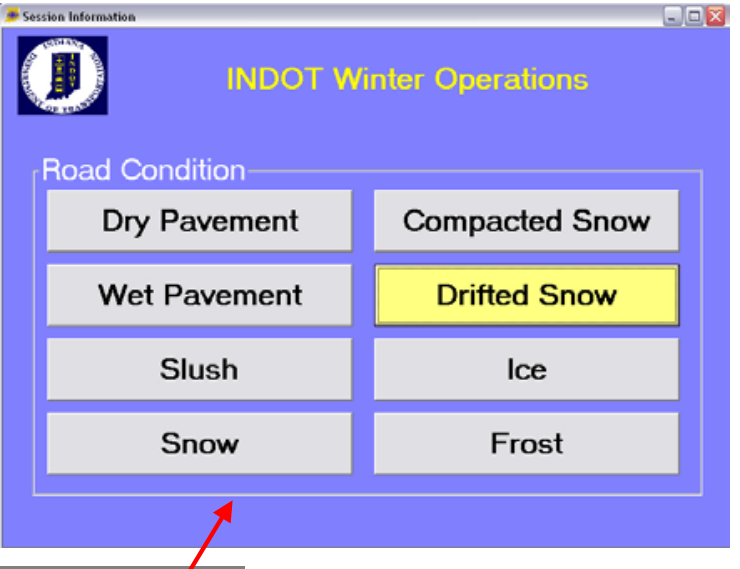

Road Conditich

Drifted Snoy,

Change

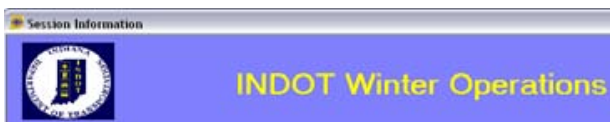

Weather Condition

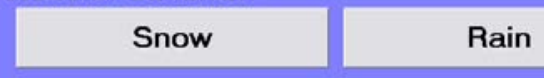

Blowing Snow

Drizzle

Sleet

Fog

\section{Freezing Rain}

No Precipitation

Weather Condit\%on

Drizzle

Change 
To report a Road Condition Problem at a particular location.

- Click on Report Road Problem button.

For Spot Chemical Application

- Click on Report Spot Mode location button.

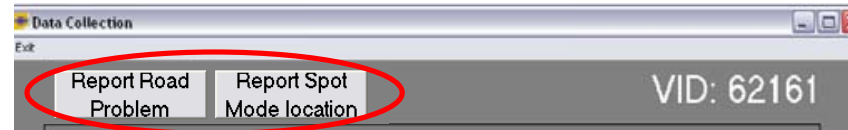

Current Mode: Plowing Only Switch mode

GPS Status:

GPS Collecting Status:

Muncie Status:

Muncie Collecting Status:

Road Condition

Drifted Snow

Weather Condition

Drizzle

Change

\section{Output Data File}

The below figure shows the data file structure that is transferred to the AVL server via wireless network. A description of these fields follows.

\begin{tabular}{|c|c|l|}
\hline Field & \multicolumn{2}{|c|}{ Definition } \\
\hline $\mathbf{1}$ & $\begin{array}{c}\text { Time } \\
\text { (hhmmss) }\end{array}$ & $\begin{array}{l}\text { Time in format of hour, minute and second. Two digits each. } \\
\text { (EST=GMT time minus 5 hours) }\end{array}$ \\
\hline $\mathbf{2}$ & $X$ (m in UTM) $)$ & $\begin{array}{l}\text { X coordinate in UTM } \\
\text { (Assumption: WGS84 Geodetic Coordinate) }\end{array}$ \\
\hline $\mathbf{3}$ & $Y$ (m in UTM) $)$ & $\begin{array}{l}\text { Y coordinate in UTM } \\
\text { (Assumption: WGS84 Geodetic Coordinate) }\end{array}$ \\
\hline $\mathbf{4}$ & UTM_Zone & $\begin{array}{l}\text { UTM zone } \\
\text { (Assumption: WGS84 Geodetic Coordinate) }\end{array}$ \\
\hline $\mathbf{5}$ & Distance $(\mathrm{m})$ & Distance traveled in meter from start of the program \\
\hline $\mathbf{6}$ & Speed $($ mph $)$ & Speed in mile per hour \\
\hline $\mathbf{7}$ & Mode & $\begin{array}{l}\text { Muncie controller mode: } \\
\text { N=Not Spreading, S=Spot, A=Auto \& M=Manual }\end{array}$ \\
\hline $\mathbf{8}$ & MPH & Current MPH \\
\hline $\mathbf{9}$ & Non blast lbs & Total non blast lbs since reset \\
\hline $\mathbf{1 0}$ & blast feet & Total blast feet since reset \\
\hline $\mathbf{1 1}$ & blast lbs & Total blast lbs since reset \\
\hline $\mathbf{1 2}$ & liquid feet & Total liquid feet since reset \\
\hline $\mathbf{1 3}$ & liquid gals $x$ & Total liquid gals x 10 since reset \\
\hline $\mathbf{1 4}$ & miles $x$ 20 & Total miles x 20 since reset \\
\hline & & \\
\hline
\end{tabular}




\begin{tabular}{|c|c|c|}
\hline 15 & road temp & Road Temperature \\
\hline 16 & air temp & Air Temperature \\
\hline 17 & product \# & $\begin{array}{l}\text { Product No.: } \\
1=\text { Sand, } 2=\text { Salt, } 3=\text { Alt } 1,4=\text { Alt 2, 5=Alt } 3 \& \text { 6=Anti Ice }\end{array}$ \\
\hline 18 & hh & Hour (2 digits) \\
\hline 19 & $\mathrm{~mm}$ & Minute (2 digits) \\
\hline 20 & ss & Second (2 digits) \\
\hline 21 & Day of week & day of week (Sunday as 1) \\
\hline 22 & month & Month (2 digits) \\
\hline 23 & Day & Day (2 digits) \\
\hline 24 & Year & Year (4 digits) \\
\hline 25 & VID & Vehicle ID (6 digits) \\
\hline 26 & Digital Ins & Check Sum number \\
\hline 27 & Boom In & 8 bit analog value \\
\hline 28 & Plow Position & Plow Position ( $0=$ up, $1=$ down $)$ \\
\hline 29 & $\begin{array}{c}\text { Road } \\
\text { Condition }\end{array}$ & Road Condition \\
\hline 30 & $\begin{array}{l}\text { Weather } \\
\text { Condition }\end{array}$ & Weather Condition \\
\hline 31 & $\begin{array}{l}\text { Chemical } \\
\text { Spread }\end{array}$ & Amount of Chemical Spread in lbs/mile \\
\hline 32 & Exception & $\begin{array}{l}\text { Exception file indicator: } \\
\mathrm{P}=\text { Plow, N=Not exception (Chemical Spread), } \\
\text { E=Road Problem, S=Spot Mode }\end{array}$ \\
\hline
\end{tabular}

Table 6 - Data File Structure

\section{GPS data (Fields 1-6)}

The longitude and latitude are transformed into UTM coordinates using the WGS84 Geodetic system. Time is converted from GMT time to Eastern Standard Time. Speed is converted from knots to mile per hour. Distance is calculated in meters.

\section{Muncie data (Fields 7-28)}

Plow position (Field 28) is determined based on the check sum number (Field 26). Chemical spread (Field 31) is calculated using the amount of chemical (blast and nonblast, Fields 9 and 11), in pounds, and miles traveled (Field 14) over the 3-minute time interval.

Data from GPS and Muncie Controller are merged with the user input data. In the case of "Report Road Problem" and "Report Spot Mode Location", only the location data will be sent to the server. 


\section{Driver Input (Fields 29 and 30)}

The driver selects a value for each field.

\section{Chemical Spread (Field 31)}

This value is calculated from Muncie fields 9, 11 and 14.

\section{Exception (Field 32)}

This field contains the exception code.

\section{File Management}

This data file is sent every three minutes over the SAFE-T network to the AVL server in Indianapolis (see Figure 2). File management software was developed to combine the truck data into a master merged text file. This merged data file is then saved to the Oracle server at a three minute interval. The map reports use the GISMAP server and ARCIMS software, developed by the INDOT GIS section, to retrieve data from Oracle and display it on state GIS maps.

\section{Map Based Reports}

The map reports display truck data in real time (3 minute delay). Also archived data can be displayed. The map application displays in layers truck speed, application time, application rate, chemical type, road condition, weather condition, and road temperature. As an example figure 6 shows the truck speed. The upper right portion of the screen is the legend that describes the symbol values used on the map.

Figure 7 shows additional truck data and how layers can be turned on and off. 


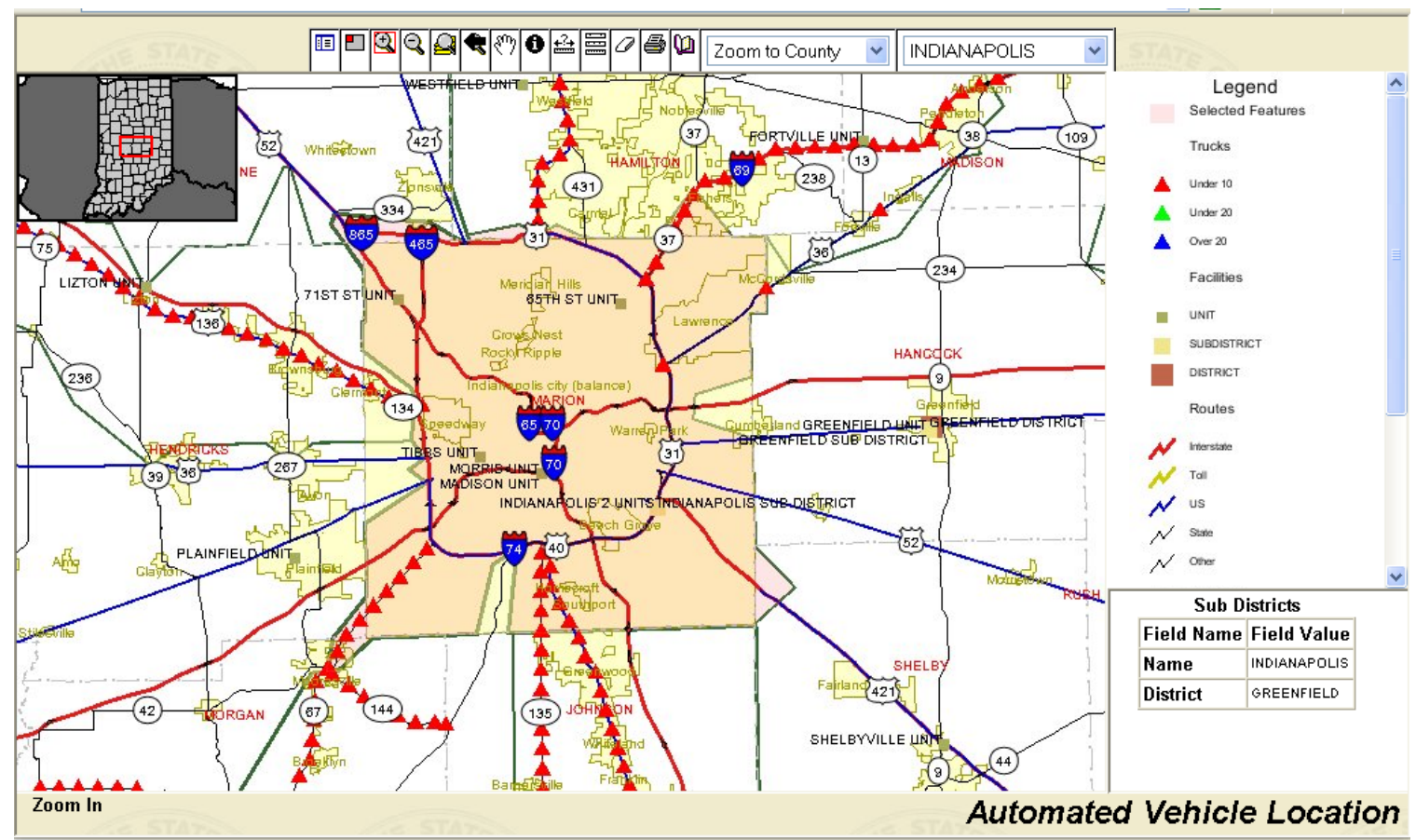

Figure 6 - AVL GIS Speed map

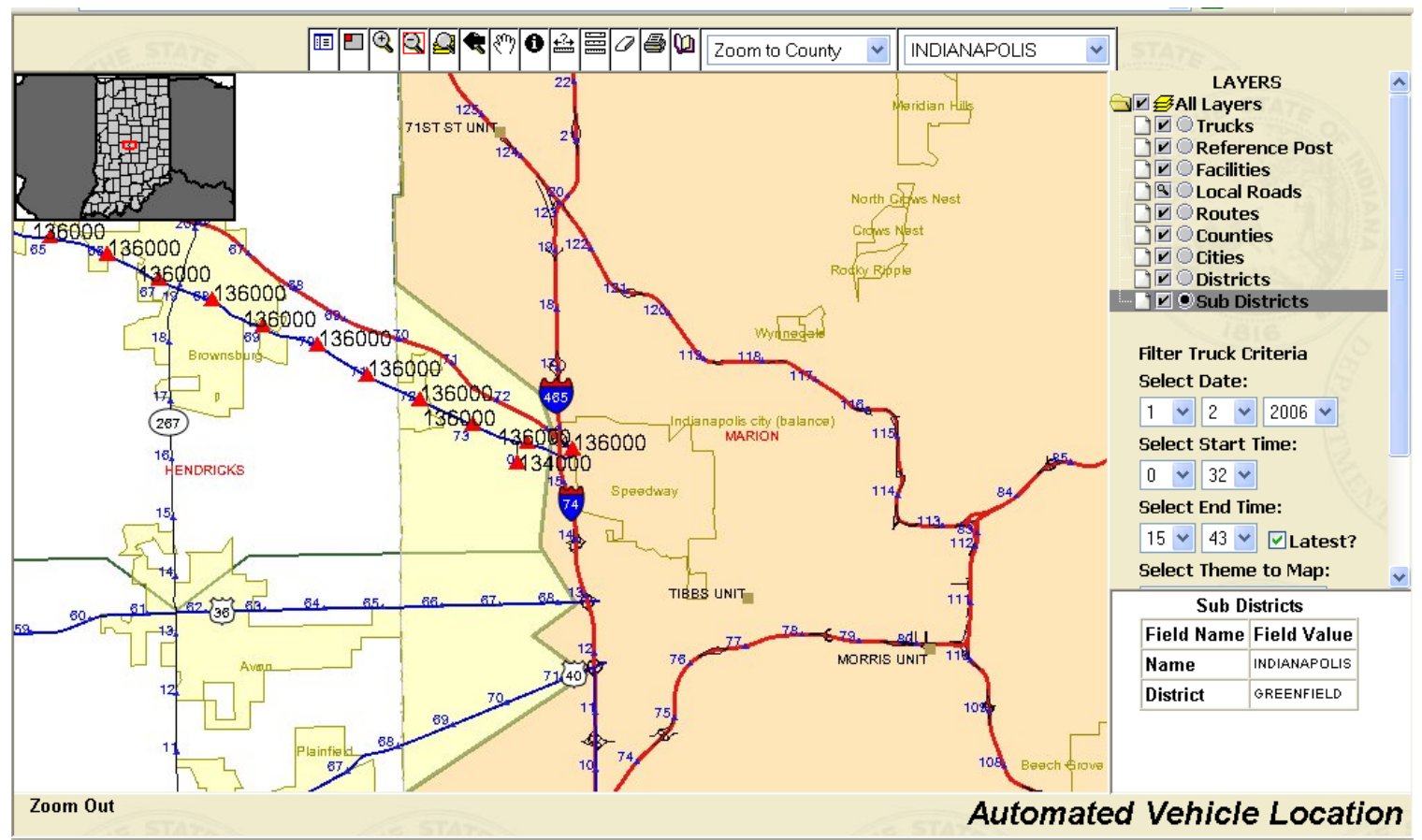

Figure 7 - AVL GIS MAP 


\section{Developing MDSS Interface}

One project activity was to develop an interface into the Maintenance Decision Support System (MDSS). This is an application developed and operated by Meridian

Environmental Technology and INDOT is participating in. The objective is to develop a transfer mechanism for the truck data to feed into MDSS.

$\underline{\text { Data Format }}$

Based on input from Meridian (Steve Gaddy), MDSS needs the following data:

- Date/Time (any common format will do)

- Vehicle ID

- $\quad$ Latitude (degrees $\mathrm{N}$ )

- Longitude (degrees W)

- $\quad$ Road Temp (degrees F)

- Air Temp (degrees F)

- Plow Position

- Road Condition

- Weather Condition

For chemical data, MDSS needs:

- Applied product (product field)

- Amount of product per lane mile such as liquid/solid rate corresponding to the product type

Since both INDOT AVL and MDSS data files are in comma separated value (CSV) format, creating the data file is fairly simple. To successfully accomplish this, the header of the two data tables should correspond so that MDSS can read INDOT AVL data files. Three possible chemical types are salt, sand, and liquids and their application amounts can be calculated from INDOT data and used in MDSS.

\section{Location Data}

GPS raw data gives the longitude and latitude in degree. To display it on the INDOT AVL maps, the units are converted from degree to X and $\mathrm{Y}$ in the UTM coordinates (Assumption: WGS84 Geodetic Coordinates in the input). MDSS needs latitude and longitude in degrees with 5 to 6 decimals, and this is provided in the INDOT data file.

\section{$\underline{\text { Options to transfer data files }}$}

MDSS collects data from a source at defined time intervals, typically every 5 minutes, but since INDOT AVL does it every three minutes Meridian uses that time interval. Meridian worked with the INDOT GIS section to develop a connection to a secure FTP 
service. The master merged data is placed there every three minutes and Meridian fetches it into MDSS.

Meridian made several tests at establishing this connection. One recommendation from Meridian is to match the headers with the data. Currently some of the headers are misaligned. Otherwise a connection was established at the end of the 06-07 winter season.

\section{Wireless Data Transfer System Using Hotspot and VPN}

Another project objective was to test the option for transferring data in batch upload through a hotspot connection. Using this method, data is collected in the truck and when the truck comes within range of a wireless hotspot a connection is made and data transferred. A hotspot could exist at the unit so when the truck returns the data transfer occurs. In this case AVL data is not real time but delayed in reporting, which is a negative with this approach. The positive is a modem or cellular device is not required in the truck for data transfer. The below figure illustrates this concept.

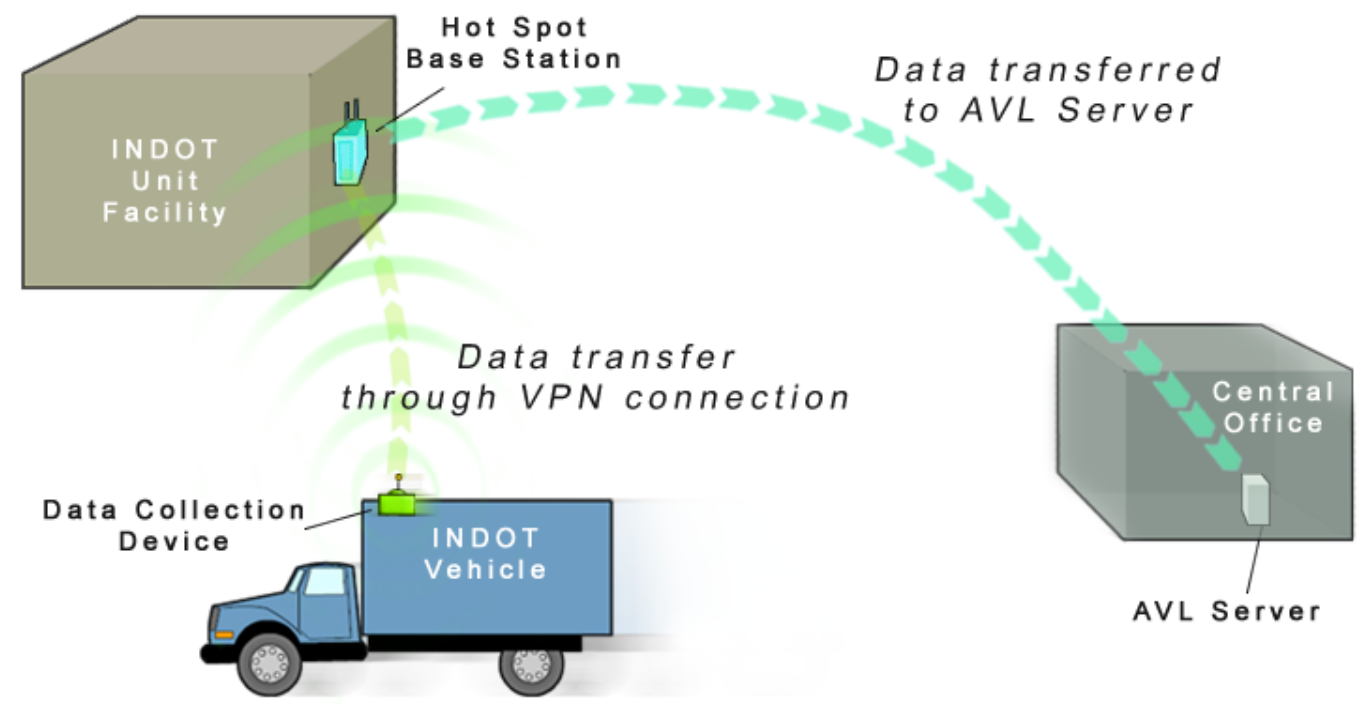

Figure 8 - Hotspot Option

Some particulars about this system and tests are provided next.

Enhanced Security with Encrypted Wireless Network and VPN Connection

The drivers are required to input ID's and passwords to access encrypted wireless network system and the Virtual Private Network (VPN) server, which provide enhanced security for data transmission from clients (vehicles) to the server (base station). 
Typically, a user (driver) is prompted to input ID and password for wireless network access. This is required for the users (truck drivers) to securely transfer their data to the base station when they enter a hotspot zone.

\section{WiFi-enabled Hotspot Using 802.11n technology}

This setup requires the following equipment:

1. Base computer

2. Wireless-N (802.11n) router

3. Laptop (Client) with wireless-N (802.11n) adapter

\section{B. Hardware Cost}

1. Linksys Wireless-N Broadband Router (WRT300N): \$149.99

2. Linksys Wireless-N Notebook Adapter (WPC300N): \$119.99

\section{Test Results}

Based on the test results, 802.11g can be used up to 35 yards and 802.11n over 90 yards for file transmission.

\section{Hotspot Reception Test (Open Area)}

\begin{tabular}{|c|c|c|c|c|c|c|c|}
\hline \multicolumn{2}{|c|}{ Distance (yd)* } & \multicolumn{2}{c|}{ Signal Strength } & \multicolumn{2}{c|}{ Speed (Mbps) } & \multicolumn{2}{c|}{ Internet Access** } \\
\hline $802.11 \mathrm{~g}$ & $802.11 \mathrm{n}$ & $802.11 \mathrm{~g}$ & $802.11 \mathrm{n}$ & $802.11 \mathrm{~g}$ & $802.11 \mathrm{n}$ & $802.11 \mathrm{~g}$ & $802.11 \mathrm{n}$ \\
\hline \hline $5-9$ & less than 5 & 5 & 5 & $2-50$ & $81-270$ & Excellent & Excellent \\
\hline $8-20$ & $5-25$ & 4 & 4 & $2-18$ & $54-108$ & Good & Excellent \\
\hline $21-24$ & $20-30$ & 3 & 3 & $1-2$ & 81 & Fair & Excellent \\
\hline $36-47$ & $30-90$ & 2 & 2 & 1 & $11-39$ & Poor & Good \\
\hline over 50 & $90-140$ & no signal & 1 & no signal & $5-26$ & no signal & Good \\
\hline- & $140-150$ & - & 1 & - & up to 11 & - & Fair \\
\hline- & over 150 & - & no signal & - & no signal & - & no signal \\
\hline
\end{tabular}

Table 7 - 802.11 Comparison

* Distance (yd): Approximate yardage 802.11g can be used up to 47 yards at maximum and 802.11n up to 150 yards at maximum from a wireless router. (802.11n about three times farther than $802.11 \mathrm{~g}$ )

** Internet Access

Excellent: No complaints in using the Internet at all

Good: Intermittent delay in navigating a webpage to another, no problems with playing streamed videos

Fair: Some stoppage in playing streamed videos, but overall okay to use the Internet

Poor: Hard to watch streamed videos and long delay to open a website 


\section{File Transmission Test (Open Area)}

\begin{tabular}{|c|c|c|c|c|c|c|c|c|}
\hline \multirow{2}{*}{ Distance (yd) } & \multicolumn{2}{|c|}{ Signal Strength } & \multicolumn{2}{c|}{ Speed (Mbps) } & duration (second)* & \multicolumn{2}{c|}{ file size (mb) } \\
\cline { 2 - 9 } & $802.11 \mathrm{~g}$ & $802.11 \mathrm{n}$ & $802.11 \mathrm{~g}$ & $802.11 \mathrm{n}$ & $802.11 \mathrm{~g}$ & $802.11 \mathrm{n}$ & $802.11 \mathrm{~g}$ & $802.11 \mathrm{n}$ \\
\hline \hline At base station & 5 & 5 & 48 & 270 & 42 & 42 & 2 & 2 \\
\hline At base station & 5 & 5 & 48 & 270 & 43 & 41 & 2 & 2 \\
\hline up to 5 & 5 & 5 & 24 & 270 & 43 & 40 & 2 & 2 \\
\hline up to 5 & 5 & 5 & 48 & 270 & 23 & 26 & 1 & 1 \\
\hline up to 5 & 5 & 5 & 48 & 270 & 21 & 26 & 1 & 1 \\
\hline up to 5 & 5 & 5 & 48 & 243 & 10 & 8 & 0.5 & 0.5 \\
\hline up to 5 & 5 & 5 & 48 & 270 & 10 & 6 & 0.5 & 0.5 \\
\hline 5 & 4 & 4 & 24 & 243 & 43 & 43 & 2 & 2 \\
\hline 10 & 4 & 4 & 2 & 270 & 42 & 42 & 2 & 2 \\
\hline 15 & 4 & 4 & 11 & 243 & 43 & 41 & 2 & 2 \\
\hline 20 & 4 & 4 & 1 & 216 & 90 & 43 & 2 & 2 \\
\hline 25 & 3 & 3 & 1 & 162 & 45 & 43 & 2 & 2 \\
\hline 30 & 3 & 3 & 11 & 135 & 43 & 43 & 2 & 2 \\
\hline 30 & 3 & 3 & 11 & 135 & 45 & 41 & 2 & 2 \\
\hline 35 & 2 & 2 & 1 & 81 & 47 & 43 & 2 & 2 \\
\hline 40 & 2 & 2 & 1 & 54 & 55 & 42 & 2 & 2 \\
\hline 50 & 2 & 2 & 1 & 39 & fail & 42 & 2 & 2 \\
\hline 70 & 2 & 2 & 1 & 39 & fail & 42 & 2 & 2 \\
\hline 90 & 2 & 2 & 1 & 39 & fail & 43 & 2 & 2 \\
\hline
\end{tabular}

* Duration (second)

Table 8 - File Transmission Test

File transmission speed was almost the same for both 802.11g and 802.11n.

\section{Secured Data Transfer Method through VPN Connection}

\section{A. VPN (Virtual Private Network)}

Virtual Private Network (VPN) is a secure, private communication system. Most VPN implementations use a public network like the Internet as Purdue VPN does. As a pointto-point connection, VPN clients authenticate users, encrypt data, and otherwise manage sessions with VPN servers utilizing a technique called tunneling. Just like Intranet users, only authorized users can access the VPN server using ID's and passwords.

\section{B. Configuring VPN Service in Windows Server 2003}

The AVL server would have to be configured as a VPN server.

C. File Transfer test result

A file transfer testing was done by transferring files from a local computer(client machine) on the Purdue network to a secured folder on a Purdue server that is running 
Windows Server 2003. With the testing, it was confirmed that the files can be transferred to the server through a secured VPN path by mapping a secured folder in the server. The users are required to input their ID's and passwords at least twice when they connect the VPN server and map the secured folder in the server. All procedures, however, can be set up automatically as long as the logins and passwords match to the VPN and the server.

\section{$\underline{\text { Summary }}$}

The use of hotspot and VPN connection provides network users with secured access to a server. Based on the tests, it was confirmed that this system provides enhanced security for data transmission from clients to the server because it requires multiple security checks to transfer files to the server. All can be set up automatically. Besides, the hotspot test results showed it is possible that the users can securely transfer their data to the base station as soon as they get into a WiFi-enabled Hotspot, over 90 yards with upcoming new wireless standard (802.11n), without having to save the data to another media and manually copying it to the base station. Therefore, this system enhances the performance of secured wireless data transmission.

\section{Using Pocket PC/Smart Phone Devices to Transfer Data}

Due to data transmission difficulties experienced with the Motorola modems, another option was explored that utilized a smart phone to transfer data. Smart phone is a mobile phone that was originally designed to have email and basic personal organizer functionalities while a pocket PC is a personal computer like handheld device with condensed functionality. Even though this option is not currently supported by INDOT it is described here.

\section{Operating Systems}

Both smart phone and pocket PC devices have different platforms, but similar functionalities. The different operating systems are Symbian, Linux, Windows Mobile, RIM and Palm OS.

The newest Windows operating system for such device is Windows Mobile 6.0 that was released in February 2007 with separate versions for each device. The smart phone version does not have touchscreen capability, the pocket PC phone version is the PDAs version with phone functionality, and the PDA version is the plain PDAs without cellular radios. Photon is the operating system that combines the pocket PC phone and the smart phone version of Windows Mobile 6. This operating system will be launched in 2008.

\section{$\underline{\text { Serial Communications }}$}

With a serial RS232 interface in these mobile devices, data transfer can be established through serial communication. This data transfer application can be developed using visual basic.net. 


\section{$\underline{\text { Wireless Data Transfer to Server }}$}

Data can be transferred from a pocket PC/ smart phone to another computer through GPRS (General Packet Radio Service). For corporate networks, a VPN (Virtual Private Network) connection is necessary. The below figure describes this method of transferring data.

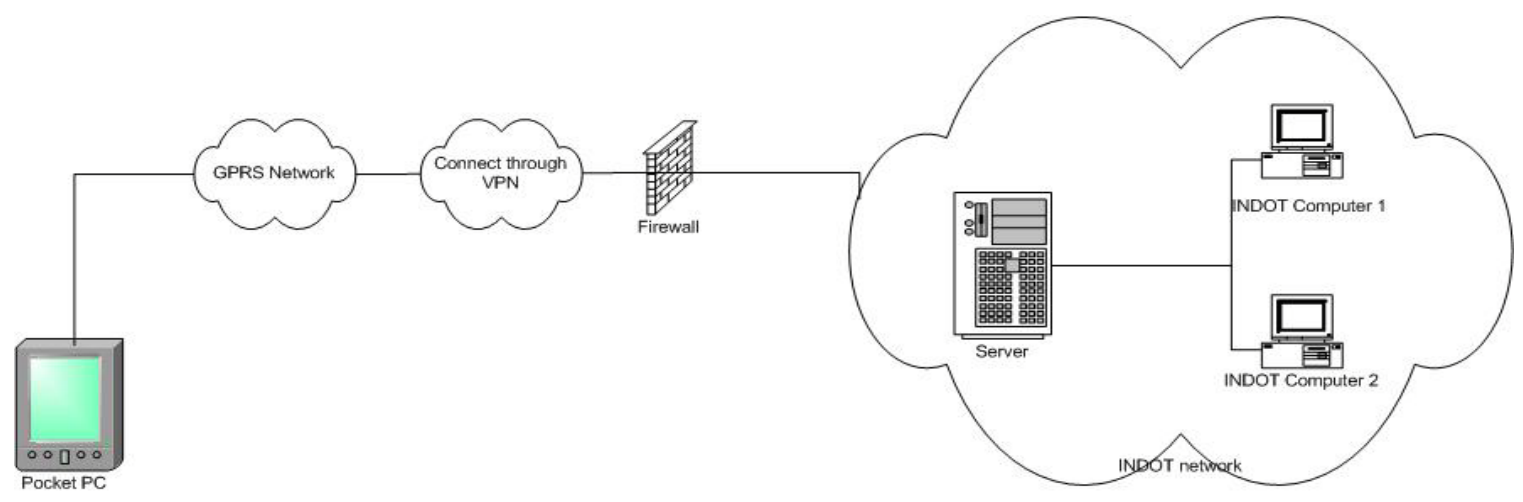

Figure 9 - Data transfer with Mobile Device

\section{System requirements for Pocket PC/ Smart Phone}

Operating System: Windows Mobile 5.0 or higher

Interface: Serial RS-232 for serial communication, Bluetooth

Data plan: GPRS data plan with capability for VPN connections

Device cost: Pocket PC phone cost is usually under $\$ 500$. This varies with service provider, the cost may be lower with service contract.

\section{Data Plan cost}

Some data plans use a public access point that does not allow VPN connections. The data plan should include a private access point that allows VPN connections to the server. The below table contains the current data plans for Cingular, Verizon and Nextel.

\begin{tabular}{|c|c|c|}
\hline Provider & Plan Name & Monthly Cost \\
\hline Cingular & $\begin{array}{l}\text { Enterprise Data } \\
\text { Connect Plan }\end{array}$ & $\begin{array}{l}\text { \$84.98 (\$44.99 plus the regular cellular plan cost } \\
\text { \$39.99) }\end{array}$ \\
\hline Verizon & $\begin{array}{l}\text { Core Connect } \\
\text { Plan }\end{array}$ & $\$ 79.99$ (\$49.99 plus the cellular plan cost) \\
\hline Nextel & $\begin{array}{l}\text { Blackberry } \\
\text { Unlimited } \\
\text { Email and Web }\end{array}$ & \$89.98 (\$49.99 plus the cellular plan cost \$39.99) \\
\hline
\end{tabular}

Table 9 - Cellular Service Comparison 


\section{$\underline{\text { Summary }}$}

In conclusion, the AVL application can be implemented through a pocket PC phone. By eliminating the computer and the wireless modem, the overall system equipment cost can be reduced dramatically. Since there are fewer hardware components involved, the installation of the equipment will be easier. The below table compares overall costs between this option(Option 1) and the Motorola option(Option 2) in 1000 trucks.

\begin{tabular}{|c|c|c|c|c|c|c|}
\hline Options & Hardware & Parts & $\begin{array}{l}\text { Model / } \\
\text { Vendor }\end{array}$ & Cost per Part & Subtotal & \begin{tabular}{|l} 
Total \\
Maximum \\
Cost
\end{tabular} \\
\hline \multirow[t]{2}{*}{$\begin{array}{l}\text { Option } \\
1\end{array}$} & 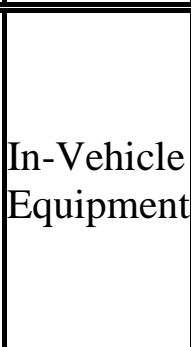 & \begin{tabular}{|l} 
GPS \\
receiver \\
+ \\
Modem \\
+ \\
Data \\
Terminal \\
\end{tabular} & $\begin{array}{l}\text { Multiple } \\
\text { Vendors }\end{array}$ & $\$ 500.00$ / vehicle & \multirow[b]{2}{*}{$\$ 3,000,000$} & \multirow[t]{2}{*}{$\$ 3,500,000.00$} \\
\hline & \multicolumn{2}{|l|}{ Service Fee } & $\begin{array}{l}\text { Multiple } \\
\text { Vendors }\end{array}$ & $\begin{array}{l}\$ 3000 / 5 \text { years / } \\
\text { vehicle } \\
(\$ 50 / \text { month / } \\
\text { vehicle })\end{array}$ & & \\
\hline \multirow{7}{*}{$\begin{array}{l}\text { Option } \\
2\end{array}$} & & \begin{tabular}{|l|} 
GPS \\
receiver
\end{tabular} & $\begin{array}{l}\text { GPS 18/ } \\
\text { Garmin }\end{array}$ & $\$ 130.00$ & \multirow{4}{*}{$\begin{array}{l}\$ 3355.00 \text { per } \\
\text { vehicle }\end{array}$} & \multirow{7}{*}{$\$ 3,753,390.00$} \\
\hline & In-Vehicle & \begin{tabular}{|l|} 
Radio \\
Modem \\
+ \\
Antenna \\
\end{tabular} & $\begin{array}{l}\text { VRM } 850 \text { / } \\
\text { Motorola }\end{array}$ & $\$ 1,900.00$ & & \\
\hline & |Еquाріпеп & $\begin{array}{l}\text { Rugged } \\
\text { Laptop } \\
\end{array}$ & \begin{tabular}{|l} 
ML 850 / \\
Motorola \\
\end{tabular} & $\$ 1,200.00$ & & \\
\hline & & \begin{tabular}{|l|} 
IP \\
Setting \\
Software
\end{tabular} & $\begin{array}{l}\text { MWCS2 / } \\
\text { Motorola }\end{array}$ & $\$ 125.00$ & & \\
\hline & Base Statio & & $\begin{array}{l}\text { AVL } \\
\text { server }\end{array}$ & $\$ 5,000$ & \multirow{3}{*}{$\$ 398,390.00$} & \\
\hline & $\begin{array}{l}\text { Map-Basec } \\
\text { Software }\end{array}$ & d Control & PU/INDOT & $\$ 0$ & & \\
\hline & \begin{tabular}{|l} 
File Transf \\
Module
\end{tabular} & & $\begin{array}{l}\text { PMDC } \\
\text { Application } \\
\text { Software / } \\
\text { Motorola }\end{array}$ & $\$ 393,390.00$ & & \\
\hline
\end{tabular}

Table 10 - Cost Comparison for 1000 trucks over a 5 Year Period 


\section{AVL Summer Applications}

\section{Paint Striping}

During summer 2007, a paint striping application that uses AVL technology was developed and tested in the Laporte District. The application records the type and locations of various paint stripes and calculates the amount(footage) of stripe and displays location information on a map. Stripe types recorded were: white skip, yellow solid, yellow solid double, yellow solid skip, and white solid.

The application consists of two VB6 programs. One runs on a standard laptop with a GPS receiver used in the escort vehicle following the paint truck and the program records the type of stripe being painted. The below screen shows the input screen, where the stripe is selected by clicking the appropriate button. Field data is collected and accumulated into a comma delimited text file.

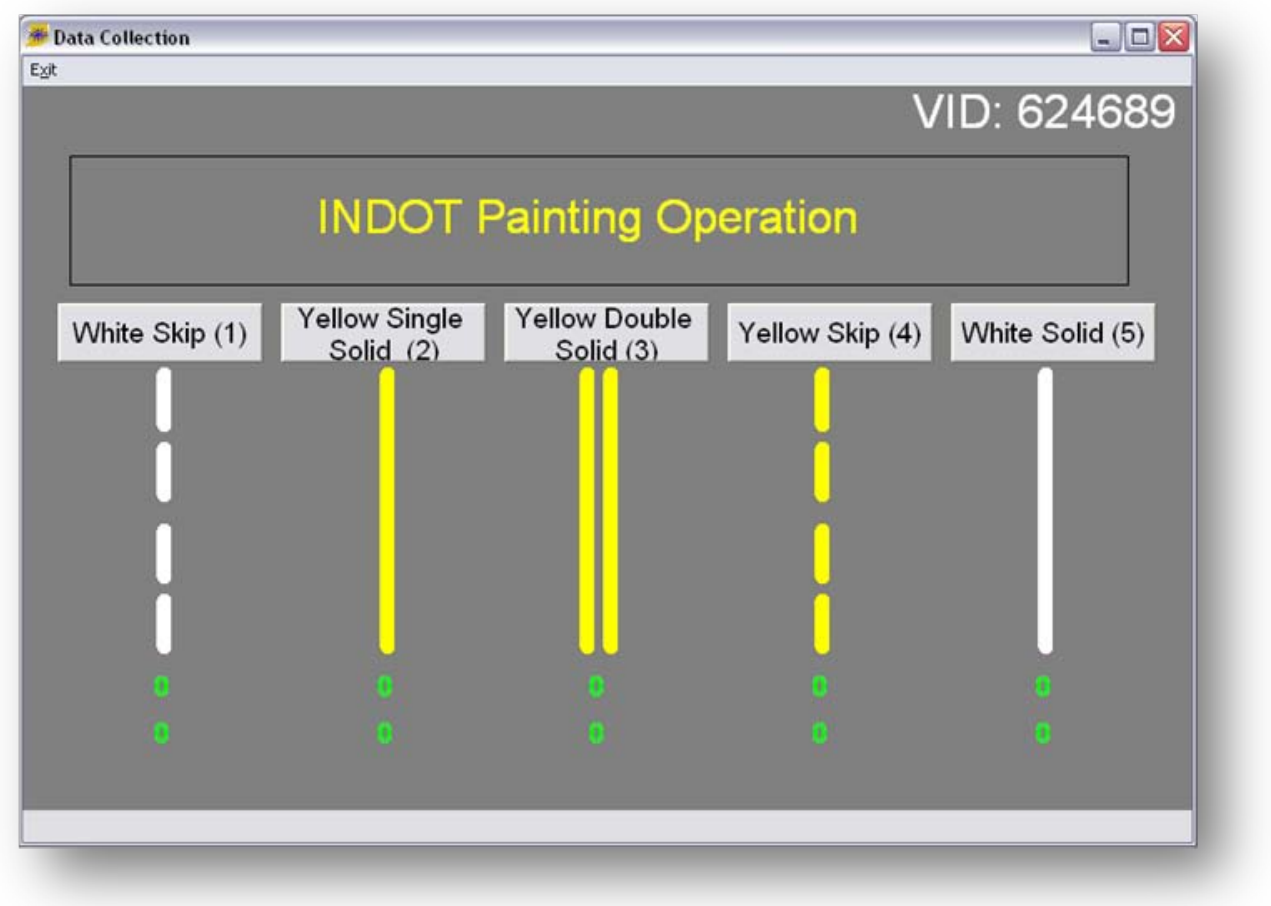

Figure 10 - Paint Stripe Input Screen

The second program runs on a desktop in the maintenance office. The data text file from the laptop is transferred to the desktop and the program calculates the amount of paint and displays painting locations on a map. The below two figures are samples of these two screen reports. 


\section{Q}
Start Date:
$6 / 21 / 2007$
End Date:
$6 / 22 / 2007$

$\begin{array}{ccccc}\text { White Skip } & \text { Yellow Solid } & \text { Yellow Solid Double } & \text { Yellow Solid Skip } & \text { White Solid } \\ 33970.13 & 5236.02 & 4062.88 & 4494.91 & 761.84 \\ & & \\ & & \\ \text { Print } & \text { Close }\end{array}$

Figure 11 - Paint Usage Calculation Screen

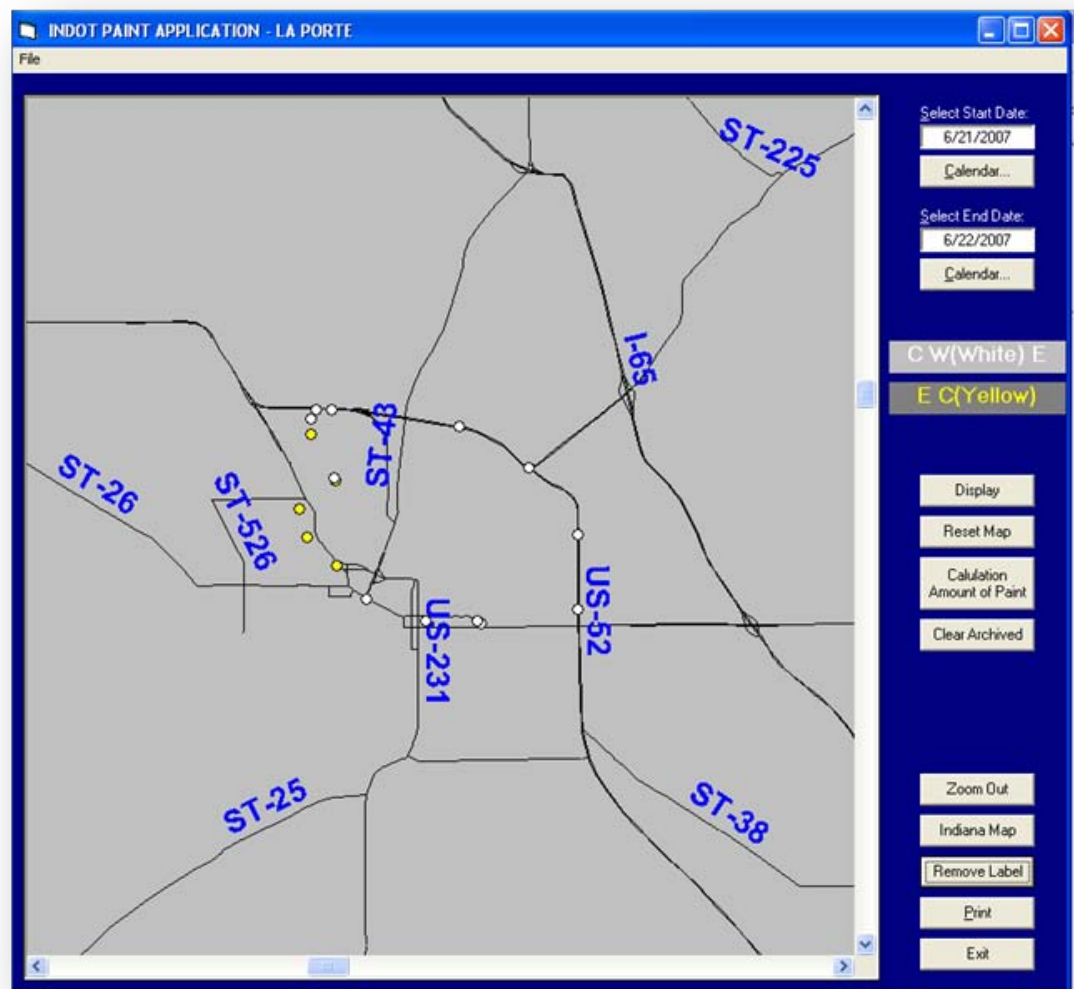

Figure 12 - Paint Stripe Location Map 


\section{Other Summer Applications}

INDOT has used AVL in other summer activities. The IWAPI units have the MDSS interface that allows the viewing of weather radar from the truck. This can be extremely helpful to crews in the field that are working on activities affected by wet weather. Crews can use the radar to determine if these activities should cease or continue.

Another possible AVL use is to interface with Work Management System forms and record field activities information at the worksite. AVL systems provide INDOT with this capability.

Since the high end systems feature touch screens the AVL equipment can be used to interface with Agile Assets Work Management reports so that reports can be completed at the work site. An expansion into non-winter activities will provide more benefits and quicker paybacks on the AVL investment. Viable applications are:

- Paint striping operations

- Chip Seals

- Crack sealing

- Crack and seat operations

- GPS feature provides the opportunity to date and locate maintenance operations

- Work Management System Reports Interface

- Mowing operations

- Herbicide operations

- Bridge repair reports

\section{Commercial AVL Systems}

This section describes commercial AVL systems used by organizations to track vehicles.

\section{Compasscom}

Compasscom has a family of products : CompassLDE, CompassTrac, CompassWorks, CompassTrac Mobile, and CompassRespond. CompassLDE receives vehicle location and discrete data for multiple fleets or mobile assets over different wireless communication networks simultaneously. CompassLDE can communicate with a variety of standard in-vehicle AVL equipment, location-enabled handsets, PDAs or other mobile sensors and serves this data in real-time to applications via the Internet or intranet using standard TCP/IP, UDP and XML protocols.

CompassTrac displays the location and status of vehicles or other mobile assets in real time on a digital map. CompassTrac can be configured with any ESRI ${ }^{\circledR}$-formatted map data. CompassTrac can display incident location and status. CompassTrac comes with an integrated reporting module. 
The CompassWorks hosted AVL solution allows monitoring and tracking your mobile assets in realtime through a web-based Citrix environment.

CompassTrac Mobile is in-vehicle software that tracks and displays vehicle and mobile asset location and status on a mobile computer. This software is ideal for public safety commanders and field managers who need to track fleets and mobile assets on laptop computers in their vehicles or in the field. CompassTrac Mobile is capable of tracking multiple fleets simultaneously by displaying the information on a mobile device.

The CompassRespond Module assists First Responders and Field Service Operations with tactical mapping and incident management needs. CompassRespond provides preplanning capabilities by locating assets on a digital map and viewing data and documents in various formats. An add-on module allows organizations to attach documents to specific GIS features important to response and service teams, such as preplans and floor plans. The CompassRespond Administration Module provides a graphical user interface that allows users to link documents to a GIS map.

This system has been used by Aurora, CO for snow removal. The snow removal application does not appear to be similar to what INDOT desires. The system tracked workers and their efforts and not chemicals.

http://www.compasscom.com/products/products.htm

\section{Grey Island}

InterFleet is a readily customizable end-to-end offering. Clients benefit from an ability to modify any or all of the core system components at any time. This includes on-board GPS/AVL hardware (and firmware), middleware, and end-user software. InterFleet provides a variety of machine-to-machine interfaces and legacy software integrations.

NextBus ${ }^{\circledR}$ solution defines the real-time transit passenger information product category. Most features and functions required by transit authorities are built-in making NextBus a dependable off-the-shelf system.

The NextBus ${ }^{\circledR}$ solution provides transit riders with the accurate arrival time of their bus using the real-time position of the vehicle. Estimated arrival times are made available over the Internet, via wireless devices such as PDA's and cell phones, through IVR (interactive voice response) and at electronic signs at specific bus stops.

Interfleet is a Canadian company and has been used by several Canadian cities and provinces for snow and ice removal.

Interfleet was contacted and a meeting with Walt Fischer, a regional director, was held. Initially, Interfleet was interested in participating in an evaluation phase, but later they pulled out. They cited problems interfacing with the Muncie controller. 


\section{http://www.interfleet.com/about.asp}

\section{IE Logistics}

Air-trak's Cloudberry system provides "off-the-shelf" hardware and software to allow tracking and communication with a mobile workforce. All of Air-trak's products are designed for integration with existing applications in mind. Air-trak has a variety of service plans available and integrates directly with ESRI ArcLogistics Route. Navtrak also provides monitoring, mapping and reporting for mobile workforces.

\section{Iwapi}

Iwapi GPS, GIS, AVL, and CAD systems can be combined with interactive touch screens, on-board camera(s), and engine, hydraulic, and other sensor feeds. They can also be combined with on-board programming, messaging, email, and networking capabilities.

Basic packages include programmable in-vehicle hardware with Linux OS, 2 GB CF internal memory, PCMCIA/CF slots, various ports, GPS puck, optional camera, store and forward capabilities, interchangeable connection cards and software for Sprint/Nextel, Verizon, Cingular/AT\&T Wireless and others, database setup, XML interfaces and flexible map options and access. The system has the ability to be operated completely without the use of the internet.

Sensors, installation, and customization are optional.

http://www.iwapi.com/AVL.htm

\section{Mentor Engineering}

Mentor Streets ${ }^{\circledR}$ Enterprise is mobile workforce management software for fleets of 100 vehicles or more. Enterprise delivers Automatic Vehicle Location (AVL)/GPS and mobile computing, captures telematic data, and includes event management and reporting capabilities.

It has not been used in snow and ice operations.

\section{http://www.mentoreng.com/products/street-enterprise/index.html}

\section{Radio Satellite integrators}

Radio Satellite Integrators' (RSI) V-Track AVL System is a fully integrated Automatic Vehicle Location system comprised of multiple subsystems:

The Mobile Subsystem is centered around the in -vehicle V-Track unit, a self-contained unit integrating GPS, wireless communications, and on-board sensors/devices. 
The Base Mapping Application can be configured in either a true client/server software program or as a Web browser-based application.

The Base Server manages all fleet communications and configuration, acts as a messaging and data transfer gateway between base-side applications and in-vehicle devices, and archives and distributes the vehicle location and status information to the mapping application either over the Web or private network. The Base Server can be located at the client site or if a web based system, it will be hosted by RSI.

The Mobile Subsystem and Base are linked via two-way wireless communications, allowing for real-time data transmission between the vehicles and the base.

RSI has been used in snow plowing, spreading, salting, and sanding primarily by municipalities.

\section{http://www.radsat.com/}

\section{Remote Dynamics}

REDIview System Features installed GPS device accurate to 10 meters (30 feet) giving minute-by-minute reporting. It also features wireless communications over the AT\&T GSM network or via the ORBCOMM satellite network. REDIview System units update continuously for real-time accuracy. Data is protected by a secure network and archived to preserve access to historical records.

REDIview has been used by fleet managers, contractors, and equipment rental companies. It has not been used in snow and ice operations.

http://www.remotedynamics.com/products/features.php

\section{Terratrak}

TerraTrak is an entry-level AVL product for vehicle tracking. It was developed as a PCbase AVL tool for owners and fleet managers who want to improve operations and reduce costs. Fleet operators can monitor vehicles in real-time with maps displays that indicate the speed, heading, and GPS-determined location down to the street level.

Fleet operators can monitor vehicles in real-time with maps displays that indicate the speed, heading, and GPS-determined location down to the street level. Vehicle location is transmitted to the Cloudberry servers using Cingular Wireless data network. The realtime vehicle positions are then displayed on PC desktop street maps. Users can replay and view routes traveled by any vehicle or the entire fleet on national, regional or metropolitan maps.

TerraTrak has not been used in snow and ice operations. 
http://www.vehiclelocationsystem.com/Product\%200verview.htm

\section{Track Star}

Track Star AVL Software is a client - server based fleet management tool that provides GPS based vehicle management capabilities to fleets of all sizes. The AVL system supports GPS devices from a variety of manufacturers including Track Star Orion, AirLink Communications PinPoint, Blue Tree Wireless and Cypress Solutions.

This system has not been used in snow and ice operations.

http://www.trackstar.com/tsavls.htm

\section{Wright Communications}

Wright Communications offers use of a real-time GPS tracking system. Wright's GPSbased tracking technology with cellular radio can be very cost-effective. It involves a one-time equipment and installation cost and a low monthly cost.

From the Wright Communications website, users can continuously track, get stop times, set geo-fences, set speed limit alerts, and view minute-by-minute basis and view the paths of each vehicle.

This system is used for vehicle location and tracking. It has a live map view and provides reporting capabilities. The system has not been used in snow and ice activities.

\section{http://www.wright2way.com/wrightcommunications_012.htm}

Most AVL systems have the same capabilities: tracking, mapping, and reporting. Interfacing with Muncie controller data is an extra function requirement. Several vendors were solicited for a trial period participation for evaluation purposes. Two vendors elected to participate: IWAPI and Zoom-Thomtech. Interfleet was interested in participating but failed to deliver during the 08-09 winter season. AVL units were obtained from IWAPI and Zoom-Thomtech and tested over the two winter periods, 07-08 and 08-09. A summary of these evaluations are next.

\section{$\underline{\text { IWAPI }}$}

IWAPI is AVL commercial software. It was successfully deployed by the state of Colorado and with the ability to push data to the truck and have a live camera feed give IWAPI some desirable features. In the 06-07 winter the Seymour District had two active IWAPI units installed in trucks. They were located in the Columbus Sub-district with one 
operating out of the Greensburg Unit and the other operating in the Amity Unit. The unit at Greensburg had good success by being able to track location, plowing info, road info and weather info from the MDSS web site. There were times when information could not be viewed at the MDSS website. The Amity unit truck experienced problems to the degree where no truck information was viewable at the MDSS site. INDOT is planning on installing 10 more units equipped with cameras.

During winter 07-08 the IWAPI system was expanded to a total of 12 units. Bill Tompkins of the Seymour District monitored these units and the following are his comments. "The systems seemed to work fairly well. We were able to track locations, view camera shots from truck, and send info to MDSS. The biggest problem is cell card coverage. The web radar sites are difficult to bring up with the cell card coverage we have. A truck needs to be in a certain location for coverage. Also, one box and camera did not work this season.

During the winter 08-09 additional IWAPI units were purchased making the total over 100. This represents about 1 in every 10 INDOT trucks. Inconsistent data transfer is the reoccurring problem with these units. Also, the maps quality is lower than what INDOT GIS maps provide.

\section{Zoom-Thomtech}

Zoom-Thomtech is another vendor of AVL equipment. Their application has the same capabilities as the Purdue and IWAPI systems. They agreed to install a total of six units in the Laporte, Fort Wayne, and Seymour Districts. As of February 2008 only one unit was installed in a Fort Wayne truck. This unit has not been sufficiently tested for a review to be formed.

During winter 08-09, units were installed and working at the locations: Amity, Columbus, Monticello, and Fort Wayne. Data was captured and successfully transferred to a Thom Tech website where it could be viewed on maps. This system has the same capabilities as IWAPI, with the exception of camera images. Data can be archived , routes tracked, and live activities viewed. One exception was AVL data was not transferred into MDSS. Technically it is feasible but Meridian was unable to accommodate during this winter season.

\section{IWAPI and Zoom-Thomtech Comparison}

Two vendors participated in the study, IWAPI and Zoom-Thomtech. ZOOM-Thomtech refers to their system as TerraFleet. How do the two vendors equipment capabilities compare? Both have high end systems with similar features. TerraFleet has another option which costs less but provides fewer features than the high end system. Due to the lower cost this option can be an AVL option for INDOT by creating a system of lower and higher end systems. A description of both options and a comparison of vendors is provided next. 
The TerraFleet base option is shown below and consists of a GPS antenna and data communications. Data communications is through cellular service. The base option tracks vehicle movement and there is no monitor. When the truck is started the system is activated.

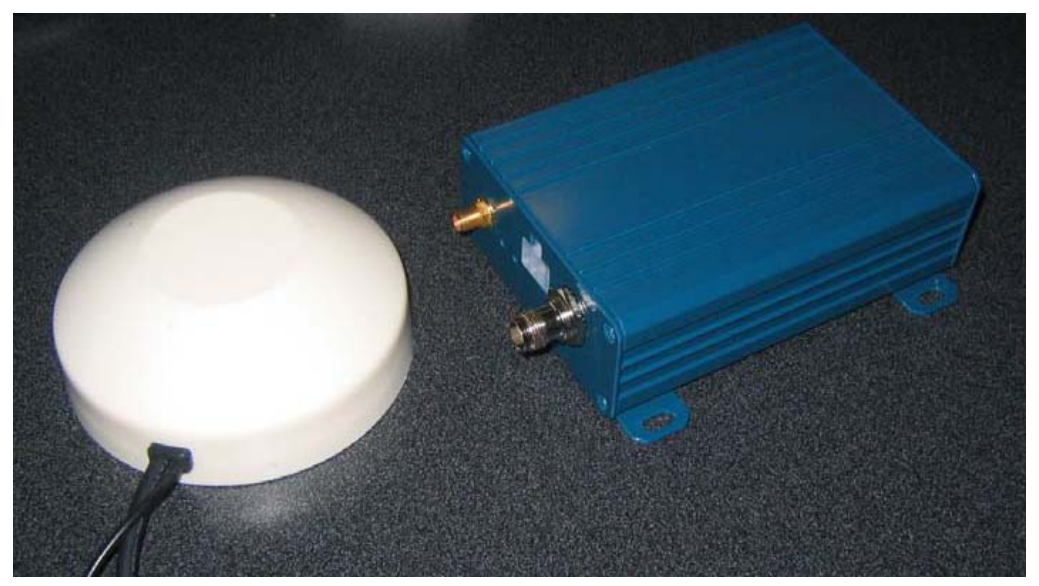

Figure 43 - TerraFleet Base Unit

The base unit can receive inputs from sensors, spreader controller, and friction meter. This data string is packaged and transferred to a Zoom-Thomtech server via cellular data network. The user can view the collected data using different report features. A data interface with MDSS is available. This unit costs \$385 and there is no driver interaction required. This unit collects data and sends it to the ZOOM-Thomtech server for processing. Table 11 shows the features and costs for the basic TerraFleet system.

\begin{tabular}{|c|c|}
\hline Feature & Cost \\
\hline GPS tracking & $\$ 385$ \\
\hline Muncie and sensor data interface & $\$ 100$ \\
\hline Friction data- RT3 interface & $\$ 200$ \\
\hline \multicolumn{2}{|l|}{ No monitor } \\
\hline $\begin{array}{l}\text { Monthly service fee for AVL services - this } \\
\text { is for AVL software from ZOOM(maps and } \\
\text { reports) }\end{array}$ & $\begin{array}{l}\$ 20 \text { - Can be eliminated if passing data to } \\
\text { MDSS. }\end{array}$ \\
\hline $\begin{array}{l}\text { Monthly service fee for passing data to } \\
\text { MDSS }\end{array}$ & $\$ 10$ \\
\hline Monthly data communication fee & $\begin{array}{l}\$ 13-\text { minimum plan, goes up for other } \\
\text { plans. }\end{array}$ \\
\hline $\begin{array}{l}\text { No driver interaction required, lessens } \\
\text { distractions. }\end{array}$ & \\
\hline
\end{tabular}

Table 41 - TerraFleet Base System

The cost for this unit is $\$ 485$ (excluding the RT3 interface) and the monthly fee is around \$25 which allows data to be posted to MDSS. 
This lower end option could be used with higher end models from IWAPI and ZoomThomtech to create an AVL system that is lower cost. This would mean that some trucks would not have the full features, however a mixture of both types could work and provide the necessary information needed in making informed decisions.

Figure 14 is the Zoom-Thomtech system.

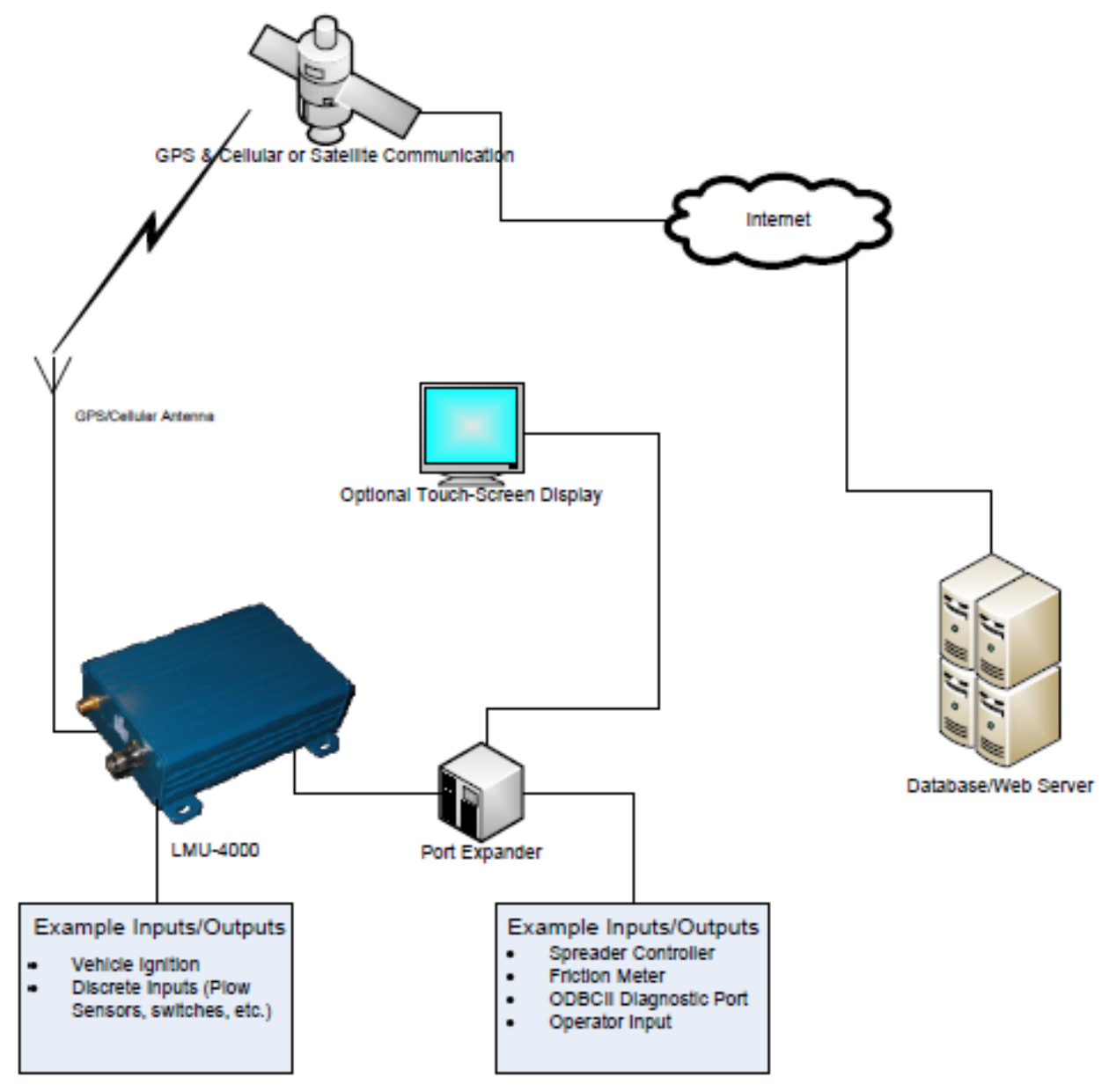

Figure 14 Zoom-Thomtech System

A touch screen display is available, see the below image which increases the cost. 


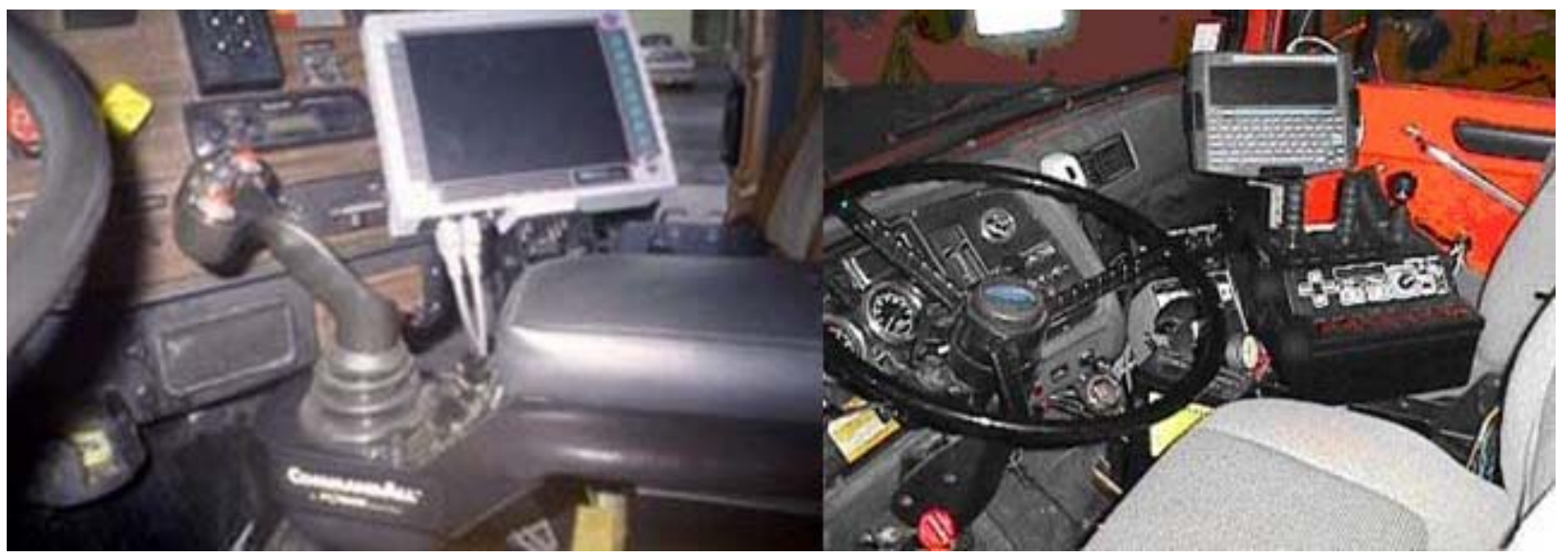

Figure 15 - TerraFleet Touch Screen System

AVL Vendor Comparison Table - IWAPI and Zoom-Thomtech Systems

\begin{tabular}{|l|l|l|l|l|}
\hline Features & IWAPI & Cost & $\begin{array}{l}\text { Zoom- } \\
\text { Thomtech }\end{array}$ & Cost \\
\hline GPS tracking & yes & $\$ 1000$ & yes & $\$ 1000$ \\
\hline Sensor data interface & yes & included & yes & included \\
\hline Muncie data interface & yes & included & yes & $\$ 100$ \\
\hline Touchscreen & yes & $\begin{array}{l}\text { Included } \\
\text { in MDSS } \\
\text { interface }\end{array}$ & yes & $\$ 300$ \\
\hline Camera & yes & $\$ 375$ & yes & $\$ 150$ \\
\hline $\begin{array}{l}\text { Driver interaction- } \\
\text { Input and } \\
\text { review(MDSS } \\
\text { interface) }\end{array}$ & yes & $\$ 700$ & $\begin{array}{l}\text { Possible , } \\
\text { but not } \\
\text { proven }\end{array}$ & $? ? ? ?$ \\
\hline $\begin{array}{l}\text { Monthly service fee } \\
\text { for AVL reporting } \\
\text { features }\end{array}$ & no & 0 & yes & $\$ 20$ \\
\hline $\begin{array}{l}\text { Interface with WMS } \\
\text { Possible }\end{array}$ & $\begin{array}{l}\text { ???? } \\
\text { proven }\end{array}$ & $\begin{array}{l}\text { Possible } \\
\text { but not } \\
\text { proven }\end{array}$ & ???? \\
\hline $\begin{array}{l}\text { Monthly fee for } \\
\text { MDSS interface }\end{array}$ & $\begin{array}{l}\text { no } \\
\text { INDOT's } \\
\text { planthly data }\end{array}$ & $\begin{array}{l}\text { Picked up } \\
\text { by } \\
\text { INDOT }\end{array}$ & yes & $\begin{array}{l}\text { yes } \\
\text { minimum }\end{array}$ \\
\hline
\end{tabular}

Table 15- AVL Comparison 
This table shows that both vendors have similar capabilities. The driver interaction feature has been used on IWAPI units but not on the ZOOM-Thomtech units, even though this is possible. This feature allows drivers to input information, like road conditions, and send with the other data. The review feature is pushing data to the vehicle to benefit the driver or operator, for example weather radar. This is a popular feature even during summer activities.

A cost comparison with similar features shows an IWAPI unit cost is $\$ 2075$ and the Zoom-Thomtech unit is $\$ 1550$. These units have a camera and touchscreen monitor. The major difference is the MDSS interface. IWAPI includes it in their price and does not add on a monthly fee. Zoom-Thomtech charges a monthly MDSS interface fee of $\$ 10$. Also, Zoom-Thomtech charges $\$ 20$ a month for their AVL software while IWAPI has no monthly charge. IWAPI's initial investment is higher but their monthly fees are lower by $\$ 10$ to $\$ 20$.

This table reveals that both vendors have similar equipment capabilities with some cost differences. Having multiple AVL vendors may not be beneficial to due to training and maintenance issues, but both vendors IWAPI and Zoom-Thomtech provide similar equipment and capabilities. The decision for INDOT is what is the correct combination of AVL equipment models, high-end and low-end? Both provide benefits to INDOT.

\section{Purdue and IWAPI Comparison}

The Purdue system failed to operate adequately on the Motorola Safe-T network as previously documented. So another option is to use a cellular data plan for data transfer which has been described. To compare the Purdue system with IWAPI two tables are used.

Table 13 compares the initial cost of the two systems. The IWAPI costs does not include a plow position sensor or road temperature sensor. Table 14 shows the monthly costs. The monthly cost difference is for the monthly AVL server charge and IWAPI has arranged lower cellular charges with a carrier. IWAPI is not currently assessing a monthly server charge, but that may be added in the future. 


\begin{tabular}{|l|l|}
\hline \multicolumn{1}{|l|}{} & Purdue AVL \\
\hline Touch Screen Laptop & 1466.43 \\
\hline GPS & 56 \\
\hline Air Card & 34.99 \\
\hline Muncie Plow sensor & 60 \\
\hline $\begin{array}{l}\text { Muncie Temperature } \\
\text { sensor }\end{array}$ & 460 \\
\hline USB to serial cord & $34.99 \times 2$ \\
\hline USB Hub & 19.99 \\
\hline Inverter & 79.97 \\
\hline Splitter & 7.99 \\
\hline & \\
\hline Total & $\mathbf{2 1 8 5 . 3 7}$ \\
\hline
\end{tabular}

\begin{tabular}{|c|c|}
\hline & IWAPI \\
\hline \begin{tabular}{|l|} 
In-vehicle Units \\
w/ MDSS Bundle
\end{tabular} & 1700 \\
\hline Wafer Cam & 350 \\
\hline 25' Cord & 20 \\
\hline $\begin{array}{l}\text { Road Watch } \\
\text { Interface }\end{array}$ & 30 \\
\hline 5' Cord & 10 \\
\hline Time & 200 \\
\hline Expense & 100 \\
\hline UPS Ground & 10 \\
\hline Total & 2420 \\
\hline
\end{tabular}

Table 13 - Initial Cost Comparison

\begin{tabular}{|c|c|c|c|}
\hline & \multicolumn{2}{|c|}{ Purdue AVL } & IWAPI \\
\hline & Unlimited Plan & 20 MB Plan & \\
\hline Data plan & 48.59 & 23.39 & $\$ 10-15$ \\
\hline $\begin{array}{c}\text { VPN client and AVL } \\
\text { server cost }\end{array}$ & 223 & 223 & N/A \\
\hline Total & 271.59 & 246.39 & $\$ 10-15$ \\
\hline
\end{tabular}

Table 14 - Monthly Cost Comparison

A feature comparison between the two options is shown in Table 15.

\begin{tabular}{|ll|l|}
\hline & Purdue AVL & IWAPI \\
\hline Touch Screen & YES & YES \\
\hline Ruggedized & NO & YES \\
\hline Moveability & YES & NO \\
\hline Muncie Interface & YES & $?$ \\
\hline $\begin{array}{l}\text { Obtain input from } \\
\text { User }\end{array}$ & YES & YES \\
\hline Camera & NO & YES \\
\hline Cellular network & YES & YES \\
\hline
\end{tabular}




\begin{tabular}{|ll|l|}
\hline Network coverage & not all & not all \\
\hline $\begin{array}{l}\text { Two-way } \\
\text { communication }\end{array}$ & NO & YES \\
\hline GPS & YES & YES \\
\hline Map & detailed & $\begin{array}{l}\text { quality not as good (can load GIS } \\
\text { map) }\end{array}$ \\
\hline Archive data & YES & YES \\
\hline Database & Oracle & SQL or Oracle \\
\hline Server & AVL server in INDOT & IWAPI individual server \\
\hline $\begin{array}{l}\text { CARS and AA } \\
\text { Interface }\end{array}$ & Possible & Possible \\
\hline
\end{tabular}

Table 15 - Purdue and IWAPI Feature Comparison

\section{Maps}

Map type and quality vary among the AVL vendors and MDSS. The AVL vendors, IWAPI and Zoom-Thomtech have flexibility with map images. Darwin Dahlgren of Zoom-Thomtech states that "one option is they can use INDOT's GIS maps dynamically from INDOT servers within our AVL system rather than loading the map statically. " Kevin Groeneweg with IWAPI states " that IWAPI map displays can use varying maps but the problem is feeding the data to MDSS which has its own proprietary maps." Steve Gaddy with Meridian Environmental says that MDSS must use open-source maps for all agencies. Therefore, currently there is no flexibility for using INDOT GIS maps or any other map source in MDSS. Currently INDOT is using MDSS maps for viewing location information.

During the 08-09 winter season a RT-3 unit was obtained and used at the Frankfort unit to collect friction data. A request was made to Meridian to display friction data in MDSS which they are not currently accommodating. Meridian says that if more agencies want friction data displayed then this will be added to MDSS. 


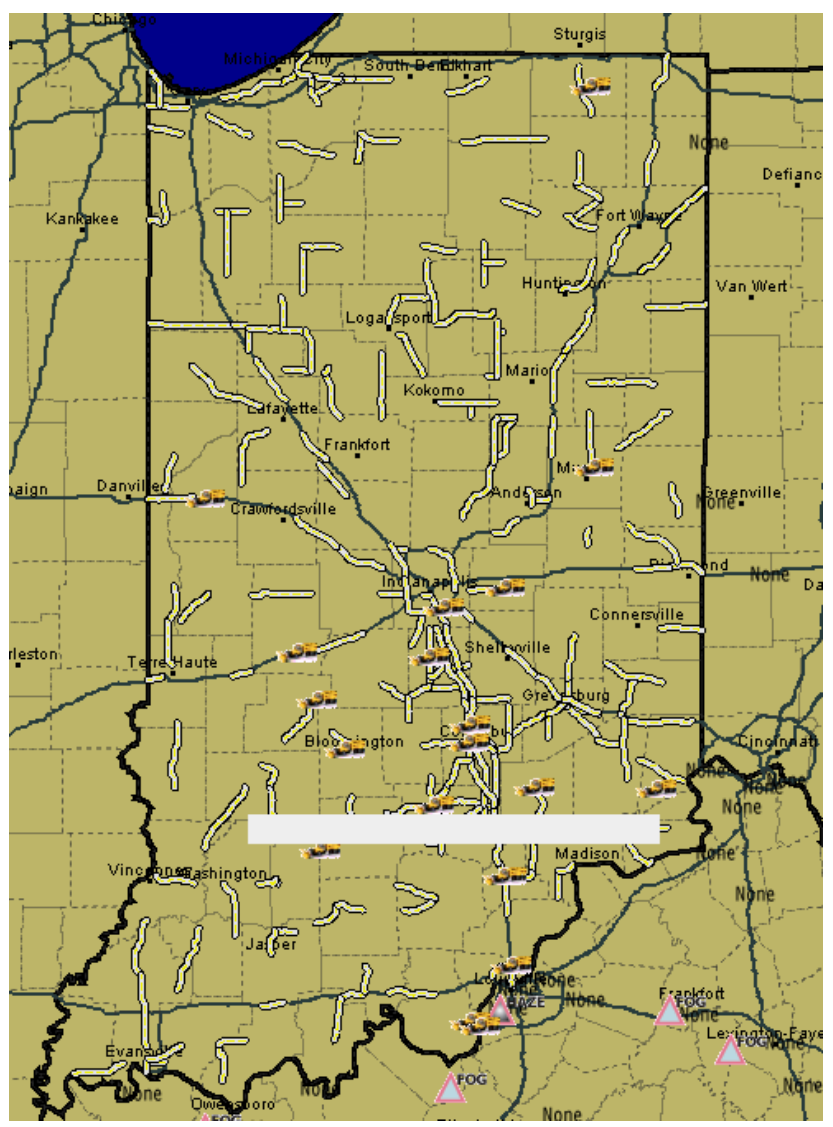

Figure 16 - MDSS Map

\section{Advantages}

AVL equipment provides many capabilities and corresponding advantages. These advantages are:

- Real-time snow and ice removal activities and data.

- Documented salt savings with data fed into MDSS.

- Historical tracking of snow and ice operations that can be used in claims against INDOT.

- Historical tracking of maintenance operations.

- Real-time weather radar.

- Real-time feedback to maintenance vehicles.

- Potential interface into Agile Assets reports.

AVL equipment should be considered as the way to bring computer-based technologies into field operations and improve record keeping while saving time. With the ability to receive data, appropriate information can be transferred to the operator or foreman that 
will save time and money in maintenance operations through informed decisions and reduced paperwork.

\section{Conclusions}

One of the main objectives was to develop and test an INDOT AVL system that utilized the statewide wireless network called SAFE-T. The system was tested over a two year winter period. Other objectives were developing an MDSS interface, a hotspot batch data transfer option, and evaluating commercial AVL systems. What transpired in this project is described in this report. The conclusions are described in this section.

The first winter season, 05-06, four trucks at two locations, 2 in Monticello and 2 in Columbus, were equipped and tested. This winter had very few winter weather events to test the system by. Also, when the system was tested several bugs and software issues were discovered. The drivers had problems logging in and determining if the truck was communicating over the wireless network. Also, they suggested modifications to the software and input screens. As a result of this testing period, changes were made to the software during the summer of 2006.. These changes were:

- Revised screen look

- Added plow position - up or down

- Added road temperature

- Added spot application and trouble spot recording

- Removed login

- Eliminated Vehicle ID input

Before the winter of 06-07, the SAC decided to expand the program to three locations and 10 trucks. Also in this expansion three different hardware data collection devices(computers) were to be tested. The testing program looked like this:

LaPorte $\quad$ - 1 Mini PC, 1 touchscreen laptop, 2 ultra mobile tablets

Monticello - 1 Mini PC, 1 touchscreen laptop, 1 ultra mobile tablet

Columbus - 1 Mini PC, 1 touchscreen laptop, 1 ultra mobile tablet

These systems were used for the whole winter season. Screen resolution, icon size and fonts were adjusted to the optimum to improve the usability of the program in the vehicle.

Winter activities in 06-07 were again below normal and most did not occur until February 2007. During this limited time field testing occurred with the following results.

1. Several problems occurred with showing data on the GIS maps. These were resolved and fixed by placing an executable program on the GIS server that archives data to Oracle and places the data on the maps.

2. Drivers experienced fewer problems with the software because it was easier to understand and operate. 
3. The modems experienced numerous problems at Monticello and Columbus due to frequency shifts which caused loss of data transfer.

4. It is difficult for drivers to monitor connection status while driving.

5. Drivers preferred laptops.

6. Data transferred successfully into MDSS.

7. The power source of the system was connected to the cigarette lighter of the vehicle for easier disassembly. Based on the evaluation, it is recommended to connect the power cables directly to the vehicle battery because of the adverse road conditions.

8. Change the GIS maps to indicate the latest position of the trucks and revise some of the legend symbols and colors.

9. Features that INDOT managers liked:

- Ability to track trucks and retrieve this information at a later date.

- Know how much chemical was placed and at what time.

- Combining the AVL info with MDSS provides better information to base decisions.

- Helps in updating the weather info.

- Provides a way that law enforcement \& private citizen could see that trucks were out on routes.

- It could be a tool to show how much time is spent on keeping roadway safe for motoring public.

- Help save on material use by having current weather info.

- Tracking employees and trucks to be able to answer calls when a truck or where a truck is on a route and better customer service.

Driver evaluations were distributed to collect their input on the system. Only one was returned with average values on the question. A sample evaluation form is included in the Appendix.

During the winter seasons 2007-2008 and 2008-2009, commercial AVL systems were installed and operated. Their use brought salt savings and improved decision-based information. Wider implementation is urged but budget constraints are currently preventing this from occurring.

\section{Recommendations}

In the end the project developed many solutions; AVL systems that utilizes a statewide wireless network and cellular data networks, MDSS, map based reports, hotspot data transfer, and a summer AVL application. But it also created many questions.

The Purdue application has many features but experienced significant problems with the wireless data network.

The commercial systems tested and explored also have data transfer issues. IWAPI and Thom Tech both experienced inconsistent data transfer. This is especially crucial for winter operations that has a need for "real-time" data. 
So what has been learned from this project, can benefits be quantified, and can anything be implemented? One obvious outcome is that the Motorola Safe-T network is not a dependable network for this application. Secondly the commercial systems data transfer is not completely reliable either however this is improving as the cellular carriers improve their networks.

What about quantifying costs and savings? Costs have been identified. Initial equipment costs are approximately \$2000. Monthly user costs depend on the vendor. For investment purposes at $\$ 2000$ each(conservative) and with a current fleet of 1100 trucks this represents an investment of over $\$ 2,000,000$. Monthly costs ( $\$ 30$ on average) would then be approximately $\$ 30,000$ or annually close to $\$ 400,000$. These monthly costs may be lower if fees could be lowered during non-winter months when activity is less. Other costs which have not been quantified but exist are developing a Muncie interface, adding sensors, improving the quality of the maps, and developing MDSS interfaces.

With the expansion of AVL units during the 08-09 winter season one observation was that maybe all trucks do not need the AVL equipment. A couple trucks at each unit could be used to track conditions, progress and performance and provide the necessary information to base management decisions during winter events. This approach would save the expense of equipping and data support for the complete fleet. Also, the fleet could be equipped with a combination of high-end and low-end systemskeeping costs down while expanding AVL capabilities.

During the 08-09 winter season INDOT attempted to determine if increasing AVL usage could save materials. During this season approximately 120 trucks were equipped with AVL, this represents approximately $10 \%$ of the fleet. An INDOT internal study (McClellan Road School 09) reveals that through February 08 and 09, INDOT consumed approximately 184,000 tons less in 09 than in 08 with comparable winter weather. The severity of the winter weather was measured in snow and freezing rain hours and for 08 and 09 it was 1324 and 1359 respectively. This salt savings has saved INDOT approximately $\$ 10$ million dollars.

What are the contributing factors for this saving? Improved management and practices certainly played a big role. Management tends to make better judgments with improved or more information. Certainly expanding the use of AVL and MDSS provided management with additional information and recommendations. It is not a stretch to say that some portion of these savings is directly attributed to the increased use of AVL and MDSS. Expanding these in operations may bring additional savings to INDOT.

Quantifying benefits is extremely difficult because of the various factors that influence costs. Other intrinsic benefits are: knowing where you have been and what you did; transferring data into MDSS so it has current conditions and is better able to make predictive assessments; have a historical archive that is well documented; and the ability with some commercial systems to push information to the drivers that helps them to better assess conditions. To improve return on investment summer applications need to be developed and utilized. One was developed and is described in this report. 
Due to the benefits experienced during the 08-09 winter season, AVL and MDSS expansion is recommended. Equipping all 1100 INDOT trucks is not currently economically feasible or recommended. But having a combination of trucks per unit AVL equipped would provide additional and current condition information to these managers that can provide a source for additional savings. 
Appendix 
Mini PC Configuration

700 TS - 7" USB Touch Screen LCD Monitor with VGA input

MP-SC3 Mini P4-Class Aluminum Mini PC

Processor: Intel Celeron $2.0 \mathrm{GHz}$

Memory: 512 MB PC 3200 DDR (256MBX2)

Hard Drive: 20 GB 4200 RPM HDD

24x CD-ROM Tray

Microsoft Windows XP Pro

Mounting Bracket

\section{Laptop Configuration}

\begin{tabular}{|c|}
\hline Fujisu LifeBook B6210 Core Solo U1400 ULV \\
\hline Memory: 2MB Cache, 512MB RAM DDR2 SDRAM \\
\hline Modem: V.9, 56 Kbps, Fax analog \\
\hline Networking: Gigabit Ethernet IEEE $802.11 \mathrm{a}+\mathrm{b}+\mathrm{g}$ \\
\hline Operating System: Win XP Pro \\
\hline $\begin{array}{l}\text { Processor: Mobile Intel 945GM Express, Data bus speed: } 533 \mathrm{MHz} \text {, Processor Speed: } \\
\text { 1.2 GHz, Intel Core Solo U1400 }\end{array}$ \\
\hline Storage: ATA-100, Hard Drive Capacity: 40GB \\
\hline $\begin{array}{l}\text { Video: } 12.1 \text { in LCD 1600x1200(ext), 1024x768(int), Intel Graphics Media Accelerat } \\
950\end{array}$ \\
\hline
\end{tabular}

Tablet Configuration

Samsung Q1 Ultra Mobile Tablet PC, Intel Celeron M, 900 MHz, ULV

Memory: 512KB L2 Cache, 512MB, 400 MHzDDR2 SDRAM

Networking: Bluetooth 2.0, Bluetooth2.0 EDR, IEEE 802.11b,g, Ethernet, Fast Ethernet, Network adapter

Operating System: Win XP Tablet PC Edition 2005

Processor: Intel Celeron M ULV, Clock Speed: $900 \mathrm{MHz}$

Storage: Mobile Intel 915GMS Express, Data Bus Speed: $400 \mathrm{MHz}$, Hard Drive Capacity: 40GB, 4200 rpm, Portable

Video: 7 in, WVGA, 800x480, Intel GMA 900 


\section{Driver Evaluation Form}

Automatic Vehicle Location Evaluations

Name:

Please circle your response.

\begin{tabular}{|c|ccc|}
\hline Location: & LaPorte & Monticello & Columbus \\
\hline Usage Frequency: & $\begin{array}{c}\text { Low } \\
\text { (during snow only) }\end{array}$ & $\begin{array}{c}\text { Medium } \\
\text { (during snow and } \\
\text { occasionally during } \\
\text { normal operation) }\end{array}$ & $\begin{array}{c}\text { High } \\
\text { (during snow as well } \\
\text { as normal operation) }\end{array}$ \\
\hline Computer Interface: & Mini PC & Laptop & Tablet \\
\hline
\end{tabular}

Rating scale: 5 being the best

Hardware

\begin{tabular}{|c|lllll|l|}
\hline Questions & \multicolumn{4}{|c|}{ Ratings } & Comments \\
\hline $\begin{array}{c}\text { Please indicate your } \\
\text { satisfaction with the hardware. }\end{array}$ & 5 & 4 & 3 & 2 & 1 & \\
\hline
\end{tabular}

Computer Interface

\begin{tabular}{|c|rrrrr|l|}
\hline Items & \multicolumn{7}{|c|}{ Ratings } & Comments \\
\hline Screen viewable size & 5 & 4 & 3 & 2 & 1 & \\
\hline $\begin{array}{c}\text { Screen resolution, size of } \\
\text { icons and font size }\end{array}$ & 5 & 4 & 3 & 2 & 1 & \\
\hline Brightness & 5 & 4 & 3 & 2 & 1 & \\
\hline
\end{tabular}

Software

\begin{tabular}{|c|c|c|c|c|c|c|}
\hline Questions & \multicolumn{5}{|c|}{ Ratings } & Comments \\
\hline $\begin{array}{c}\text { Please indicate your overall } \\
\text { satisfaction with the software. }\end{array}$ & 5 & 4 & 3 & 2 & 1 & \\
\hline User friendliness & 5 & 4 & 3 & 2 & 1 & \\
\hline $\begin{array}{l}\text { Do you have any additional } \\
\text { comments? Please explain. }\end{array}$ & & & & & & \\
\hline
\end{tabular}


Final Report

FHWA/IN/JTRP-2009/11

\title{
AUTOMATED VEHICLE LOCATION (AVL) FOR ROAD CONDITION REPORTING
}

\author{
by \\ Bob G. McCullouch \\ Principal Investigator \\ Research Scientist \\ Michelle Leung \\ Web Multi-Media Developer \\ and \\ Won Jin Kang \\ Web Multi-Media Developer \\ School of Civil Engineering \\ Purdue University \\ Joint Transportation Research Program \\ Project No. C-36-67ZZZ \\ File No. 9-10-77 \\ SPR-2922 \\ Conducted in Cooperation with the \\ Indiana Department of Transportation \\ and the Federal Highway Administration \\ U.S. Department of Transportation
}

The contents of this report reflect the views of the authors, who are responsible for the facts and the accuracy of the data presented herein. The contents do not necessarily reflect the official views or policies of the Indiana Department of Transportation or the Federal Highway Administration at the time of publication. This report does not constitute a standard, specification, or regulation.

Purdue University

West Lafayette, IN 47907

September 2009 